NBER WORKING PAPER SERIES

\title{
THE ELECTORAL ADVANTAGE TO INCUMBENCY AND VOTERS' VALUATION OF POLITICIANS' EXPERIENCE: A REGRESSION DISCONTINUITY ANALYSIS OF ELECTIONS TO THE U.S.HOUSE
}

\author{
David S. Lee \\ Working Paper 8441 \\ http://www.nber.org/papers/w8441 \\ NATIONAL BUREAU OF ECONOMIC RESEARCH \\ 1050 Massachusetts Avenue \\ Cambridge, MA 02138 \\ August 2001
}

Matthew Butler provided outstanding research assistance. I thank John DiNardo for numerous invaluable discussions, and Josh Angrist, Jeff Kling, Jack Porter, Larry Katz, Ted Miguel, and Ed Glaeser for detailed comments on an earlier draft. I also thank seminar participants at Harvard, Brown, UIUC, UW-Madison and Berkeley for their additional useful suggestions. The views expressed herein are those of the author and not necessarily those of the National Bureau of Economic Research.

(C) 2001 by David S. Lee. All rights reserved. Short sections of text, not to exceed two paragraphs, may be quoted without explicit permission provided that full credit, including (C) notice, is given to the source. 
The Electoral Advantage to Incumbency and Voters' Valuation of Politicians' Experience:

A Regression Discontinuity Analysis of Elections to the U.S. House

David S. Lee

NBER Working Paper No. 8441

August 2001

JEL No. D70, D72, J00

\begin{abstract}
$\underline{\text { ABSTRACT }}$
Using data on elections to the United States House of Representatives (1946-1998), this paper exploits a quasi-experiment generated by the electoral system in order to determine if political incumbency provides an electoral advantage - an implicit first-order prediction of principal-agent theories of politician and voter behavior. Candidates who just barely won an election (barely became the incumbent) are likely to be ex ante comparable in all other ways to candidates who barely lost, and so their differential electoral outcomes in the next election should represent a true incumbency advantage. The regression discontinuity analysis provides striking evidence that incumbency has a significant causal effect of raising the probability of subsequent electoral success - by about 0.40 to 0.45 . Simulations using estimates from a structural model of individual voting behavior - imply that about two-thirds of the apparent electoral success of incumbents can be attributed to voters' valuation of politicians' experience. The quasi-experimental analysis also suggest that heuristic "fixed effects" and "instrumental variable" modeling approaches would have led to misleading inferences in this context.
\end{abstract}

David S. Lee

Department of Economics

UC- Berkeley

549 Evans Hall, \#3880

Berkeley, CA 94720-3880

and NBER

dslee@econ.berkeley.edu 


\section{Introduction}

An essential element to the principal-agent approach to understanding politician and voter behavior is the notion that political incumbents act in ways to raise their chances of re-election and to further their political careers. A number of economic analyses have considered the various mechanisms through which this might occur. For example, incumbents may influence tax and expenditure policy or monetary policy, use the office to sell political favors in exchange for campaign contributions, or vote on legislation in a way that reflects the ideological make-up or economic interests of their constituencies; these things are done in order to persuade voters to support their re-election bids. ${ }^{1}$ There is an implicit empirical prediction common to many of these hypotheses. Winning an election, by definition, allows a politician to be the incumbent. In turn, only an incumbent has the advantage of choosing actions available to an elected official; any nonincumbent candidate, by definition, cannot choose these actions. Thus, if the incumbent's actions are meant in part to gain electoral support, then winning an election (and hence becoming the incumbent) should have a reduced-form positive causal effect on the probability of being elected in a subsequent election.

To what extent does that causal relationship hold empirically? The political science literature has been careful to recognize that answering this question, and measuring the true electoral advantage to incumbency, is not as straightforward as the casual observer might think. ${ }^{2}$ Through-

1 Studies that adopt a principal-agent framework in examining the political economy of elections and politician behavior is too voluminous to review here. The following are only a few examples of studies that consider such hypotheses. Rogoff [1990], Rogoff and Sibert [1988], and Alesina and Rosenthal [1989] consider how incumbents may manipulate fiscal or monetary policy to gain electoral support. Besley and Case [1995a,b] consider the tax and expenditure-setting behavior of incumbents, and Levitt and Poterba [1994] consider how Congressional Representation might effect state economic growth and the geographic distribution of federal funds. Levitt [1996] considers the relationship between constituent (and own) interests and ideology and politician voting behavior in Congress. This is also the focus of the studies of Peltzman [1984, 1985], and Kalt and Zupan [1984]. That politicians are behaving in a way (potentially by catering to special interests groups) to raise campaign funds, to raise re-election chances is implicitly or explicitly examined in Levitt [1994], Grossman and Helpman [1996], Baron [1989], and Snyder [1990]. 2 The empirical literature in political science that addresses the measurement of the incumbency advantage is large. Examples of studies that consider the potential selection bias problems include Erikson[1971], Collie [1981], Garand and Gross [1984], Jacobson [1987], Payne [1980], Alford and Hibbing [1981], and Gelman and King [1990]. 
out the latter-half of the 20th century, Representatives in the U.S. House who sought re-election were successful about 90 percent of the time. ${ }^{3}$ However, incumbents may enjoy re-election success for reasons quite apart from their incumbency status. After all, there are many potential reasons why politicians become incumbents in the first place. As one example, Democrat incumbents may be more successful than Democratic challengers, not because there is an inherent advantage to incumbency, but simply because Democrat incumbents tend to represent districts that are heavily Democratic. In general, persistent heterogeneity across Congressional districts in the partisan make-up of voters could, by itself, generate the observed 90 percent incumbent re-election rate. ${ }^{4}$ No structural advantage to incumbency is needed to explain this empirical fact.

Using data on elections to the United States House of Representatives (1946-1998), this paper produces quasi-experimental estimates of the true electoral advantage to political incumbency by comparing the subsequent electoral outcomes of candidates (and their parties) that just barely won elections to those of candidates (and their parties) that just barely lost elections. Under mild continuity assumptions, these two groups of candidates are, as one compares closer and closer electoral races, ex ante comparable in all other ways (on average) except in their eventual incumbency status. The research design approximates, to some degree, the ideal (and infeasible) classical randomized experiment that would be needed to test the incumbency advantage hypothesis, and hence the implicit prediction of many political agency theories. The identification strategy is recognized as an example of the regression discontinuity design, as described by Thistlethwaite and Campbell [1960] and Campbell [1969], more recently implemented in Angrist and Lavy [1998] and van der Klaauw [1996], and formally examined as an identification strategy in Hahn, Todd, and van der Klaauw [2001]. In addition to providing an empirical test of the incumbency advantage hypothesis, I derive a simple structural model of the individual voter's valuation of political

3 Jacobson [1997, p. 22].

4 I sometimes refer to this alternative story as a "spurious" incumbency effect. 
experience that permits an interpretation of the magnitude of the estimated effects.

The empirical analysis yields the following findings. First, incumbency has a significant causal effect on the probability that a candidate (and her political party, in general) will be successful in a re-election bid; it increases the probability on the order of 0.40 to $0.45 .^{5}$ The magnitude of the effect on the two-party vote share is about 0.08 . These findings are consistent with the firstorder "reduced-form" prediction of a prototypical principal-agent model of the electoral process. ${ }^{6}$ Second, after accounting for the apparently important selection bias, losing an election reduces the probability of running for office in the subsequent period, by about 0.43 , consistent with an enormous deterrence effect. Third, under the maintained assumptions of a particular structural model of individual voting behavior, the estimates imply that voters place a fairly modest value on politicians' experience when evaluating political candidates. One additional term of Congressional experience (relative to the opposing candidate) would lead to a 2 or 3 percent increase in the vote share. On the other hand, small magnitudes in terms of the vote share can have enormous impacts on the eventual election outcomes. A simulation using the structural estimates imply that most (two-thirds) of the apparent electoral success rate of incumbent parties could be explained by a political experience advantage that incumbents typically hold over their challengers. Finally, I show evidence that in this context, an alternative "instrumental variable" approach, as well as a "fixed effect" analysis of the same data would lead to misleading inferences.

The paper is organized as follows. Section 2 reviews the stylized facts of incumbency and re-election in the U.S. House of Representatives in the latter half of the 20th century. Section 3 provides an illustration of how the regression discontinuity design accounts for selection bias in testing the structural incumbency hypothesis, and establishes the continuity assumptions that are

5 As discussed below, the causal effect for the individual that I consider is the effect on the probability of both becoming a candidate and winning the subsequent election. Below I discuss the inherent difficulty in isolating the causal effect conditional on running for re-election.

6 For example, the framework of Austen-Smith and Banks [1989], as discussed below. 
crucial to the research design. Section 4 reports the main reduced-form estimates of the causal effects of incumbency. Section 5 develops a structural framework for interpreting the magnitude of the effects in terms of the individual voter's valuation of politicians' experience. In section 6 , I compare the main estimates to that obtained from alternative "differencing" and "instrumental variable" approaches to identification. Section 7 concludes.

\section{The Electoral Success of Incumbents - Advantage or Artifact?}

For the U.S. House of Representatives, in any given election year, the incumbent party in a given congressional district will likely win. The solid line in Figure I shows that this re-election rate is about 90 percent and has been fairly stable over the past 50 years. $^{7}$ Well-known in the political science literature, the electoral success of the incumbent party is also reflected in the two-party vote share, which is about 60 to 70 percent during the same period. ${ }^{8}$

As might be expected, incumbent candidates also enjoy a high electoral success rate. Figure I shows that the winning candidate has typically had an 80 percent chance of both running for re-election and ultimately winning. This is slightly lower, because the probability that an incumbent will be a candidate in the next election is about 88 percent, and the probability of winning, conditional on running for election is about 90 percent. By contrast, the runner-up candidate typically had a 3 percent chance of becoming a candidate and winning the next election. The probability that the runner-up even becomes a candidate in the next election is about 20 percent during this period.

The casual observer is tempted to take these figures as evidence that there is an electoral $a d-$ vantage to incumbency - that winning has a causal influence on the probability that the candidate will run for office again and eventually be elected. However, the difference between the subsequent

7 Calculated from data on historical election returns from ICPSR study 7757. See Data Appendix for details. Note that the "incumbent party" is undefined for years that end with ' 2 ' due to decennial congressional re-districting.

8 See, for example, the overview in Jacobson [1997]. 
electoral outcomes of the winning and runner-up candidates may be due, perhaps entirely, to the fact that these two groups of candidates are not ex ante comparable in important ways.

Table I illustrates the point empirically. The first row and column indicates that the winner of any given election at time $t$ (i.e. the incumbent for election $t+1$ ) has about a 0.803 chance of both running in and winning election $t+1$. Runner-up candidates have a 0.025 percent chance. But winning candidates prevailed over their opposition for various reasons. Perhaps they are more charismatic, or they had more campaign resources. Another simple explanation is that voters in the winner's congressional district tend to vote in favor for the winner's party, regardless of the candidate. Whatever the reason, it is clear from the third column of Table I that the eventual winners of election $t$, are more "experienced" than the eventual runner-up candidates of election $t$. In these data, even before election $t$ is held, the eventual winners, on average, already have served 3.798 terms in office, compared to 0.270 terms for the eventual runner-up candidates. Thus, the difference in subsequent electoral outcomes for these two groups is perfectly consistent with no effect of winning, when the candidates are ex ante non-comparable, as the empirical evidence appears to strongly suggest.

Table I also shows that winning candidates are more likely than runner-up candidates to become a candidate in the next election (second column). However, it is also the case that the winning candidates were more "experienced" candidates in the first place; winning candidates of election $t$ have had many more attempts at gaining office than their runner-up counterparts (fourth column). This is perfectly consistent with no effect of winning on the propensity to run for office again, as long as there are systematic differences between the winners and losers of election $t$ in their propensities to run for election, as the data strongly suggest.

The lower part of Table I shows that whether or not candidates attempt to run again for office, the Democratic vote-share in the next election is on average about 0.702 in districts where 
Democrats won in election $t$, about 0.35 more than in the districts where the Democrat candidate was the runner-up in election $t$. The interpretation of this 0.35 vote share swing as a causal effect of the Democrats winning office is questionable, especially since the data indicate that in any given election, winning Democratic candidates run in districts that in the past have tended to be more favorable to Democrats, compared to their runner-up counterparts (fourth column). ${ }^{9}$

Establishing whether or not the differences in electoral outcomes between incumbents and non-incumbents represent a true causal effect or a simple artifact of selection is important first step to assessing the empirical relevance of theories that adopt a principal-agent approach to modeling politician-voter interactions. The premise of this approach is that politicians, while in office, strategically choose policies and actions to raise their chances of re-election, and voters discipline the politicians' actions with the implicit threat of voting them out of office. A finding that there is no structural advantage to incumbency would be at odds with the predictions of theories that adopt this framework.

For example, consider the model of electoral accountability and incumbency of AustenSmith and Banks [1989]. In this model, there are 2 identical and competing candidates, one "representative" voter, and there are two periods. In a single period, candidates announce platforms, the voter then chooses the candidate, the incumbent then chooses an effort level, and then there is a random shock that, combined with the incumbents' effort level, produces a policy outcome, over which the voter's preferences are defined. Austen-Smith and Banks show that, under certain conditions, a subgame perfect Nash equilibrium arises where the threat of dismissal (and the potential gain to staying in office) induces the incumbent to exert effort while in office in the first period.

\footnotetext{
9 For the sake of conciseness, the rest of the empirical analysis in the paper focuses on comparing Democratic winning candidates to Democratic losing candidates. This is done to avoid the "double-counting" of observations, since in a largely two-party context, a winning Democrat will, by construction, produce a losing Repbulican in that district and vice versa. (It is unattractive to compare a close winner to the closer loser in the same district) In reality, there are third-party candidates, so a parallel analysis done by focusing on Republican candidates will not give a literal mirror image of the results. However, since third-party candidates tend not to be important in the U.S. context, it turns out that all of the results are qualitatively the same, and are available from the author upon request.
} 
The result is that the incumbent has a higher probability of winning the election in period 2, even though the candidates are ex ante identical. A finding that there is no true electoral advantage would be at odds with this reasonable model of electoral accountability. At the least, the finding of no effect (or a negative effect) of incumbency should provide some reason to reconsider how we model incumbents' incentives and behavior while in office.

\section{Identification of the Causal Effects of Incumbency}

\subsection{Graphical Analysis}

This paper examines the data in a way that can distinguish between the proposed causal effect of incumbency and the artifact of pure selection. Even though winning and losing candidates are likely to be systematically ex ante different in important ways, it is highly plausible that winners of elections who win by a very slim margin are likely to be ex ante comparable to candidates who barely lose the election by a very slim margin. In the extreme case, among all political elections that are decided by 1 vote, the winners and the losers of those elections would almost certainly be, on average, ex ante comparable. In practice, virtually no elections are decided by one vote. However, if the relationship between the observed vote share and subsequent electoral outcomes is sufficiently "continuous" and "smooth", one can estimate the average outcomes for these hypothetical 1-vote victories and defeats, using data from cases where the margin of victory (or defeat) is greater than 1 vote. ${ }^{10}$ The idea of exploiting cases when a treatment variable is a deterministic function of an observed variable in order to credibly estimate causal effects originates in Thistlethwaite and Campbell [1960]. Here, the nature of an election (the candidate with the most votes wins, and becomes the incumbent) provides the deterministic function, and the observed

\footnotetext{
10 Ironically, the empirical analysis may actually benefit from the fact that these extreme "photo-finish" cases are very rare. It is easy to imagine that if all elections were decided by a handful of votes, many would be contested, and it could be that those candidates who are better at the "post-election" battle - for recounts, for example - may be systematically different, ex ante, from those who lose the "post-election" battle.
} 
variable is the vote share.

Figure IIa illustrates the regression discontinuity in the incumbency context. It plots the estimated probability of both running in and winning election $t+1$ as a function of the vote share margin of victory of a candidate in election $t$. Each point is an average of the indicator variable for running in and winning election $t+1$ for each interval, which is 0.005 wide. Points to the left of the dashed vertical line represent subsequent electoral outcomes for the losing candidate in election $t$; those to the right are for the winners.

As apparent from the figure, there is a striking discontinuous jump, right at the 0 point, indicating that bare winners of elections are much more likely to run for office and win the next election than the bare losers. As long as the bare winners and bare losers are ex ante comparable (on average) in all other ways, the difference can properly be interpreted as the causal effect of winning election $t$. The causal effect is enormous: about 0.45 in probability. It is important to note that nowhere else does a jump seem apparent. The data exhibit a well-behaved continuous and smooth relationship between the two variables, except at the threshold that determines victory and defeat.

Figures IIIa, IVa, and Va present the analogous pictures for three other subsequent electoral outcomes: whether or not the candidate in election $t$ becomes a candidate in election $t+1$, the Democratic vote share (whether or not the candidate runs for re-election) in election $t+1$, and whether or not the Democratic candidate (whoever it is) wins in election $t+1$. All figures exhibit significant jumps at the threshold. They imply that the causal effect of winning an election is to raise the probability of becoming a candidate in the next election by about 0.40 . The incumbency advantage for the Democratic party appears to be about 7 or 8 percent of the vote share. In terms of the probability that the Democratic party wins the next election, the effect is about 0.35 .

In all four figures, there is a noticeable positive relationship between the margin of victory 
and the electoral outcome. For example, as shown in Figure IVa, the Democratic vote share in election $t$ is positively associated with the Democratic vote share in election $t+1$, both before and after the threshold. This provides a sense of the importance of "selection bias". Clearly, comparing the means of the outcome variables between the left and right-hand side of the threshold yields severely biased measures of the incumbency advantage. Note also that in Figures IIa, IIIa, and Va, there appears to be important curvature in the data so that a heuristic linear least squares approach, where the outcome is regressed on a dummy variable for victory while "controlling" for the vote share in election $t$, will give somewhat misleading inferences. ${ }^{11}$

\subsection{Refutability}

Knowing the function that determines the status of the endogenous regressor (here, incumbency) does not - by itself - guarantee that the gap depicted in Figures IIa, IIIa, IVa, and Va represents a causal effect. The crucial assumption for the causal interpretation is that all observable and unobservable pre-determined (relative to election $t$ ) characteristics that could influence election $t+1$ are not systematically different between the winning and losing candidates of election $t$.

As an example of what might invalidate the causal inference, suppose that prior to election $t$, given any two candidates potentially running against each other, all agents knew with certainty the exact vote count and outcome that would occur if any pair of candidates were to run against each other. If this were the case, we might expect that those candidates who choose to become a candidate in an election which they know they are going to lose by 1 vote, to be systematically different from the group of candidates who choose to become a candidate in an election which they know they are going to win by 1 vote. Perhaps these winners happen to have, on average, more charisma than these losers. Then, any difference in the average outcomes between these two

11 The exception is Figure IVa, where the relationship looks fairly linear; however this is the case as long as one focuses on the data lying between -0.25 and 0.25 . By using only this data, such a heuristic regression approach can be thought of as a non-parmaeteric local linear estimate of the gap using a bandwidth of 0.50 . 
groups in election $t+1$ may be entirely due to a difference in inherent "charisma" and not at all due to the incumbency advantage. Charisma, obviously, is only one example, and there are numerous other dimensions in which bare winners and losers in this case may be systematically different.

Outcomes of political elections, especially the ex post close ones, are likely to have important unpredictable aspects to them; the exact vote share is never thought to be known before the election, so it is unlikely that this particular counterexample has any real-world importance. Nevertheless, the more general point still stands: if there is a strong reason to believe that the bare winners of election $t$ are systematically ex ante different from the bare losers of election $t$, there would be some reason to question the internal validity of the interpretation of the discontinuity jump as a causal effect.

Ultimately, a credible assessment of the extent to which this might be a problem relies upon data. If bare winners and bare losers are fundamentally non-comparable, it is likely that they will look different based on observable pre-determined characteristics, especially those characteristics that tend to be correlated with the electoral outcomes in election $t+1$. Thus, this research design is refutable, and the extent to which the pre-determined characteristics do differ is the extent to which we should place some doubt on the internal validity of the research design

Put another way, if the regression discontinuity design is valid (bare winners and losers are ex ante comparable in all other ways), then any pre-determined characteristics must not be systematically different between the bare winners and losers. Bare winners and losers should have similar levels of congressional or electoral experience. Bare winners and losers of elections should face opposing candidates with the same level of experience. Bare winners and losers should be in districts that have the similar levels of political strength for their party (as proxied by their party vote share or whether their party won in a previous election $t-1$ ). This is analogous to the strong prediction of an experiment that randomizes treatment and control; in the randomized experiment, 
the baseline characteristics of the experimental subjects should not be, in any ex ante observable way, systematically different from the control subjects.

Figures IIb, IIIb, IVb, and Vb provide evidence which seems to corroborate the validity of the regression discontinuity design in this context. There is a strong positive relationship between the margin of victory in election $t$ and 1) past political experience, 2) electoral experience (the number of times the candidate has run for election in the past), 3) the Democratic vote share in $t-1$, and 4) whether the Democratic party won election $t-1$. However, Figure IIb shows, for example, that bare winners and losers have, on average the same amount of accumulated congressional experience by time $t$. There are also no visible discontinuities at the threshold for electoral experience, the previous Democratic vote share or previous victory indicator. Close winners and losers do appear to be quite comparable along these four dimensions; these facts lend credibility to the identification strategy employed in this study. ${ }^{12}$

\subsection{Reduced-form Specification: sufficient stochastic restrictions}

Before presenting the detailed results from the formal estimation procedure and drawing positive conclusions, I formally establish the stochastic assumptions sufficient for identification of the true incumbency effect in this context.

Consider the following reduced-form econometric specification ${ }^{13}$

$$
V S_{j t+1}=\alpha_{t+1}+I N C_{j t+1} \beta+\mu_{j t+1}
$$

where $V S_{j t+1}$ is the vote share that the Democratic Party attains in congressional district $j$ at election $t+1 . I N C_{j t+1}$ is an indicator variable for whether the Democratic party is the "incumbent party" for that district and election. $\mu_{j t+1}$ is a stochastic error term that represents all other ob-

\footnotetext{
12 Obviously, just as it is impossible to "prove" that the randomization "worked" in a classical randomized experiment, it is also impossible to "prove" that the close winners and losers are ex ante comparable in all other ways.

13 It is "reduced-form" in the sense that at this point I do not model the indvidiual voter's decision. I defer this to Section 5. Also note that for ease of exposition, I abstract from the fact that the dependent variable is bounded between 0 and $1 . \mathrm{I}$ also return to the issue in Section 5.
} 
servable and unobservable determinants of the vote share, and $\beta$ is the "structural" parameter of interest - the true party incumbency effect. ${ }^{14}$

The important point to recognize (and is the essence of the regression discontinuity design) is that we know the deterministic function that determines incumbency status $I N C_{j t+1}$. The party with the most votes in election $t$ becomes the incumbent party in election $t+1$. This function is

$$
I N C_{j t+1}=\left\{\begin{array}{l}
1 \text { if } V S_{j t}>\frac{1}{2} \\
0 \text { if } V S_{j t}<\frac{1}{2}
\end{array}\right.
$$

The simple comparison of the $t+1$ vote shares between the incumbent and non-incumbent party is then

$$
E\left[V S_{j t+1} \mid I N C_{j t+1}=1\right]-E\left[V S_{j t} \mid I N C_{j t+1}=0\right]=\beta+B I A S_{t+1}
$$

where

$$
B I A S_{t+1}=E\left[\mu_{j t+1} \mid \mu_{j t}>\frac{1}{2}-\alpha_{t}-I N C_{j t} \beta\right]-E\left[\mu_{j t+1} \mid \mu_{j t}<\frac{1}{2}-\alpha_{t}-I N C_{j t} \beta\right]
$$

which should be recognized as a form of the canonical characterization of selection bias when dummy variables are endogenous. ${ }^{16}$

Rather than try to model $B I A S_{t+1}$ in terms of observable variables, the notion in the regression discontinuity approach is to compare vote shares between parties that just barely became and barely missed being the incumbent. By doing this, we obtain

$$
E\left[V S_{j t+1} \mid V S_{j t}=\frac{1}{2}+e\right]-E\left[V S_{j t+1} \mid V S_{j t}=\frac{1}{2}-e\right]=\beta+B I A S_{t_{+1}}^{*}
$$

where

$$
B I A S_{t_{+1}}^{*}=E\left[\mu_{j t+1} \mid \mu_{j t}=\frac{1}{2}+e-\alpha_{t}-I N C_{j t} \beta\right]
$$

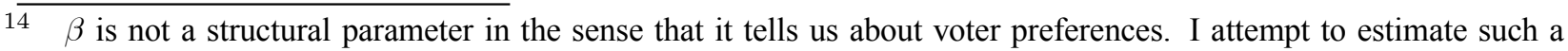
structural parameter in a later section. Here, $\beta$ refers to the reduced-form causal effect of incumbency on the voteshare for the party in the next election.

15 For ease of exposition, I abstract from the existence of third parties. Generalizing to account for those thrid parties is carried out in the empirical results.

16 See Heckman [1978].
} 


$$
-E\left[\mu_{j t+1} \mid \mu_{j t}=\frac{1}{2}-e-\alpha_{t}-I N C_{j t} \beta\right]
$$

and $e$ represents how "close" the elections in $t$ are.

Clearly, when $\mu_{j t+1}$ and $\mu_{j t}$ are jointly continuously distributed, then $B I A S_{t+1}^{*}$ vanishes as $e$ gets smaller and smaller (we examine closer and closer elections). The goal in the estimation procedure is to use the data to estimate the limit of $E\left[V S_{j t+1} \mid V S_{j t}=\frac{1}{2}+e\right]-E\left[V S_{j t+1} \mid V S_{j t}=\frac{1}{2}-e\right]$ as $e$ approaches 0 . That $\mu_{j t+1}$ and $\mu_{j t}$ is jointly continuously distributed is a very weak stochastic restriction that is implicitly standard in virtually every econometric model that models a continuous outcome variable. ${ }^{17}$ What makes this approach particularly appealing is that it is unnecessary to specify assumptions about the correlation between $\mu_{j t+1}$ and $I N C_{j t+1}$ or between $\mu_{j t+1}$ and some candidate instrument.

\section{Estimation of the Causal Effects of Incumbency}

Table II illustrates that as one compares closer and closer elections, winning and losing candidates look more similar, and suggests that the selection bias in the naive comparison of winning and losing candidates can be quite large. In the first set of columns we see that the Democrats obtain about 70 percent of the vote share in election $t+1$ when they win office in election $t$, compared to about 35 percent of the vote when they lose. At the same time, on average, winning Democrats in any given election year typically have about 3.8 terms of congressional experience and have run in about 4 elections prior to time $t$, compared to 0.26 terms of experience and 0.46 elections for the losing Democrats. ${ }^{18}$

The second set of columns demonstrate that the differences remain large when focusing

\footnotetext{
17 Or models a continuous latent index. Also, note tha the necessary identifying assumption is much weaker. ONe simply needs that the conditional expectation function of $\mu_{j t+1}$ with respect to $\mu_{j t}$ to be continuous at the point $\frac{1}{2}-\alpha_{t}-I N C_{j t} \beta$.

18 The "opposition" party is defined as the party (other than the Democrats) with the highest vote share in $t-1$. Almost all of the time this is the Republican party.
} 
on the three-fourths of the sample in which the margin of victory is less than 50 percent of the vote. The probability of Democrats winning election $t+1$ remains large at 0.88 for winners in $t$, compared to the 0.10 for the losers of election $t$. And similarly, there remains a large difference, for example, in the average electoral experience (the number of times a candidate has run in an election as of year $t$ ), with a difference in favor of the winners of about 3.50 attempts.

A substantial portion of the differences go away when focusing on the 10 percent of the elections that is decided by less than 5 percent of the vote, as shown in the third set of columns in Table II. In this sample, the average difference in political and electoral experience between the Democratic winners and losers is about 0.65 years, much smaller than in previous columns. However, important differences persist: the winning Democrat candidate is significantly more likely (by about 0.14 in probability) than a losing candidate to be in a district where the Democrats had won the election in $t-1$. Moreover, the differences in all of the pre-determined characteristics (the variables in the 3rd through 8 th rows) remain and are statistically significant. It is important to recognize, however, that this is to be expected: the sample average in a narrow neighborhood of a margin of victory of 5 percent is in general a biased estimate of the true conditional expectation function when that function has a nonzero slope (which it appears to have, as illustrated in Figures II and III).

The approach in this paper is to estimate a flexible parameterization of the function leading up to and after the threshold, in order to estimate the mean electoral outcome at the threshold from the left and from the right. For example, I regress the Democrat vote share $t+1$ on a 4 th-order polynomial in the margin of victory in election $t$, separately, for the sample of winners in election $t$ (3818 observations) and for the sample of losing candidates at $t$ (2740 observations). For indicator variables, such as whether or not the Democratic party won in $t+1$, I estimate a logit with a 4 th order polynomial in the margin of victory, separately, for the winners and the losers. 
Figures II, III, IV, and V all visually demonstrate that this procedure appears to perform reasonably well. The regression and logit predictions do seem to line up well with the local averages plotted in the figures. In particular, Figure IIIa suggests that the data ask for different kinds of curvature on either side of the threshold. ${ }^{19}$

The final set of columns in Table II demonstrate that this procedure makes all of the differences in the pre-determined characteristics between the winners and losers vanish, as exactly predicted by the assumptions of the regression discontinuity design. In the third to eighth rows, all of the differences are small and statistically insignificant. ${ }^{20}$ By contrast, differences in the electoral outcome variables - the Democrat vote share and whether the Democrats win in $t+1$ - remain large and statistically significant. They imply a true electoral incumbency advantage of about 8 percent in terms of the vote share, and about 0.36 in the probability of winning election $t+1$.

If the bare winners and losers are in all other ways ex ante comparable near the discontinuity threshold, then the estimated incumbency advantage is predicted to be invariant to the inclusion (and in the way they enter) of pre-determined characteristics as covariates. Table III shows this to be true: the results are quite robust to various specifications. Column (1) reports the estimated incumbency effect on the vote share, when the vote share is regressed on the victory (in election $t$ ) indicator, the quartic in the margin of victory, and their interactions. The estimate should and does exactly match the differences in the first row of the last set of columns in Table II. Column (2) adds to that regression the Democratic vote share in $t-1$ and whether they won in $t-1$. The

\footnotetext{
19 In principle, it would be more attractive to view this as a nonparametric estimation problem, where the parameter of interest is the conditional expectation function just to the left and right of the threshold. It would also be more attractive to utilize an automatic bandwidth selection procedure to determine the optimal amount of smoothing. However, even the so-called "automatic" data-based bandwidth selection procedure for the optimal (in the MSE sense) bandwidth at a particular point in the support of the regressor requires as an input an initial subjective smoothing parameter. See Fan and Gijbels [1996]. An assessment of the finite-sample performance of these procedures is beyond the scope of this study. Instead, I assume that all of the functions belong to the class of fourth order polynomial (interacted with winner/loser) for the regressions and logits. Statistical inference is straightforward in this framework. It simply involves estimating the standard error of parameteric predictions at the threshold.

20 This is favorable for the research design in the same way it would be comforting to see that the baseline characteristics between experimental and control subjects are on average the same in a classical randomized study.
} 
Democratic share in $t-1$ comes in highly significant and statistically important. The coefficient on victory in $t$ does not change. The coefficient also does not change when the Democrat and opposition political and electoral experience variables are included in Columns (2)-(5).

The estimated effect also remains stable when a completely different method of controlling for pre-determined characteristics is utilized. In Column (6), the Democratic vote share $t+1$ is regressed on all pre-determined characteristics (variables in rows three through eight), and the discontinuity jump is estimated using the residuals of this initial regression as the outcome variable. The estimated incumbency advantage remains at about 8 percent of the vote share. Finally, in Column (7) the vote share $t-1$ is subtracted from the vote share in $t+1$ and the discontinuity jump in that difference is examined. Again, the coefficient remains at about 8 percent.

Column (8) reports a final specification check of the regression discontinuity design and estimation procedure. I attempt to estimate the causal effect of the impact of winning in election $t$ on the vote share in $t-1$. Since we know that the outcome of election $t$ cannot possibly causally effect the electoral vote share in $t-1$, the estimated impact should be zero. If it significantly departs from zero, this calls into question, some aspect of the identification strategy and/or estimation procedure. The estimated effect is essentially 0 , with a fairly small estimated standard error of 0.011. All specifications in Table III were repeated for the indicator variable for a Democrat victory in $t+1$ as the dependent variable, and the estimated coefficient was stable across specifications at about 0.38 and it passed the specification check of Column (8) with a coefficient of -0.005 with a standard error of 0.033 .

By way of summarizing the results, Table IV reports the estimated causal effects of incumbency using the three other outcome measures that were examined in Figures IIa, IIIa, IVa, and Va. All estimates use the full specification of Column (5) in Table III. The first two entries in the top panel show that, at the individual candidate level, winning an election increases the probability that 
the candidate will run for office again and be successful by about 0.45 in probability. It increases the probability of becoming a candidate in the next election by about 0.434 . It is important to emphasize that these are not simple associational correlations. They represent the kind of causal effects - quite plausibly free of unobservable selection bias - that can strongly suggest that their losing may have a real deterrence effect on the decision to run for office. ${ }^{21}$ If the politician is making an expected utility calculation, this suggests that either the perceived payoffs or probabilities of winning (or both) shift against the runner-up quite significantly.

It is also important to note that since losing has an enormous impact on even attempting to run for office, it will be virtually impossible to convincingly estimate the candidate-level incumbency advantage in terms of the advantage for the individual candidates, conditional on the candidates running again in election $t$, without fully understanding the unobservable process that determines the candidate's decision to run for office. ${ }^{22}$ This is because we will never observe the vote share for candidates who choose not to pursue elected office. This is analogous to the inherent difficulty in estimating a treatment effect in a classical randomized experiment when most of the controls drop out of the sample.

On the other hand, the fact that candidates drop out as a consequence of the outcome of the election is, in principle, part of the incumbency advantage. Thus, using the outcome variable that was examined in Figure IIa (the probability that a candidate both runs in and wins election $t+1$ ) allows estimation of the combined advantage of office, and the advantage gained through deterring candidates from even running.

Moreover, the true incumbency advantage for the party in a congressional district is welldefined, because typically some other candidate will replace any past challengers who drop out of

$21 \quad$ Such a possible deterrent effect is discussed in Levitt and Wolfram [1997].

22 For the approaches that attempt to tackle this difficult issue, refer to the sample selection literature beginning with e.g. Heckman [1979] and Gronau [1977]. 
politics. ${ }^{23}$ The third and fourth entries in the top panel of Table IV indicate that the causal effect of the Democrat winning office is to raise the Democrat vote share by 0.078 in the next election, and raise the probability that the Democratic candidate will win by 0.385 .

The results make clear that the electoral success of incumbents is not an artifact of selection, and hence the evidence is at least broadly consistent with the reduced-form prediction of many political agency hypotheses that incumbents successfully utilize the opportunities embodied in elected office to gain re-election. ${ }^{24}$

Finally, the lower panel of Table IV shows that there is little evidence that these estimated incumbency effects vary by sub-groups defined by the amount of political experience that the candidate possess at election $t$. It would be interesting to know if the incumbency advantage diminishes or increases as we consider more and more experienced candidates. For example, a finding that the incumbency advantage disappeared when considering candidates that have already been in office for a number of terms would be consistent with the notion of a signaling mechanism [Rogoff 1990], where incumbents pursue policies to signal their type (good or bad) to voters. However, the results are somewhat mixed. While the point estimates of the incumbency effects do appear smaller for more experienced candidates in three of the four electoral outcome measures, it is also true that the F-test in each case fails to reject equality of the coefficients across these sub-groups. This suggests that any empirical analysis that purports to sort out these second order effects will require much more data than that used in this analysis.

\section{An Econometric Model of Voters' Implicit Valuation of Political}

\footnotetext{
23 And even in the case where no candidate runs for the party, it is not unreasonable to assign " 0 " to the vote share attained by the party in that district and year.

24 Strictly speaking, political agency theories have yet to explicitly model the dynamic of how a candidate within a party is chosen, and how candidates decide to run with the expectation of how the party will support them. However, ignoring those inter-party dynamics, the "agent" could be heuristically defined as the set of possible candidates for a party within a congressional district, where the party in power pursues actions that are implicitly rewarded by voters.
} 


\section{Experience}

In this section I develop a simple structural model of individual voting behavior for the purpose of providing an economic interpretation of the magnitudes of the estimates of the incumbency advantage. The analysis thus far has addressed the first-order, difficult issue of disentangling a true electoral return to holding office from an obscuring unobservable selection process. This paper does not attempt to make empirical conclusions about the precise mechanism by which the incumbency advantage arises. Much richer data is required for such an endeavor. ${ }^{25}$

Instead, I explore what kind of institutional and behavioral assumptions can be imposed on the data in order to make statements about the nature of voter preferences within an economic model of utility-maximizing voters. In particular, I presume (and do not test the hypothesis) that the incumbency advantage is simply reflective of the underlying preferences of the voters for politicians' level of congressional experience, as measured by the number of terms the politician has served in the House of Representatives. Voters directly value the ability of a politician to engage in the legislative process, and the goal is to estimate that valuation in terms of Congressional terms of experience. When a candidate wins an election, she will automatically have one more term of experience than a candidate that is otherwise identical, but who lost the election. In the model, if voters value that extra year of experience, the winning candidate, and hence incumbent, will have an electoral advantage in the next election.

\subsection{Institutional Framework}

I assume a two-party system, with candidates for the House of Representatives for each party in

\footnotetext{
25 Possessing arguably credible estimates of this incumbency advantage is a first step towards deepening our understanding the causal mechanisms of the electoral advantage. Given that the findings are broadly consistent with the implications of political agency theories, it will be a fruitful avenue for research to subject these various theories to further empirical tests - while simultaneously addressing important selection issues that typically make it difficult to distinguish between association and causation. This will require detailed data on measurable politician actions: ultimately we cannot empirically distinguish between various hypothesized mechanisms of political agency with election returns data alone.
} 
each Congressional district. In each period, the candidates can choose to run for office, and if they choose not to run, the party always finds a replacement. Each party announces a national party "platform" to which the candidates of each party uniformly agree. Citizens vote for the candidates. I do not model the detailed process of how the platform arises, but I do assume that once in office, no single politician can influence the party platform. In any given election year $t+1$ the Democratic platform is represented by the scalar $\delta_{t+1}$ and the Republican platform by $\rho_{t+1}$, normalizing $\delta_{t+1}>\rho_{t+1}$.

\subsection{Voters}

Suppose that in any congressional district $j$ at election $t+1$, we can represent individual voter $i$ 's political preference by the scalar $\varepsilon_{i j t+1}$; higher $\varepsilon_{i j t+1}$ represents more liberal preferences. It is taken as exogenous, with $\varepsilon_{i j t+1} \sim N\left(a_{j t+1}, 1\right)$, so that preferences are heterogeneous within district and year, but the location of the distribution varies arbitrarily across districts and over time. The preferences of an individual voter is unobservable to politicians, and prior to the election in $t+1, a_{j t+1}$ itself is unpredictable, even if politicians possess estimates or forecasts of $a_{j t+1}$ (through polls).

Assume that citizens' voting is influenced by only two factors: 1) the relative "closeness" of the announced national party platforms to their own political preferences, and 2) the relative Congressional experience $\Delta E X P_{j t+1}$ (normalized as the Democrat's political experience minus that of the Republican, and measured in number of Congressional terms) between the two candidates.

The individual's propensity to vote Democrat is represented by the index

$$
\gamma \Delta E X P_{j t+1}+\varepsilon_{i j t+1}
$$

with the value of candidates' Congressional experience denoted by $\gamma, \gamma>0$. The vote $v_{i j t+1}$ of 
individual $i$ in district $j$ at election $t+1$ is described by

$$
v_{i j t+1}=\left\{\begin{array}{c}
\text { Democrat if } \gamma \Delta E X P_{j t+1}+\varepsilon_{i j t+1}>\frac{\delta_{t+1}+\rho_{t+1}}{2} \\
\text { Republican otherwise }
\end{array}\right.
$$

So, for example, if there is no political experience difference between the two candidates, voters will choose based on which national party platform is "closer" to their own political preference. But if $\triangle E X P_{j t+1}>0$ (the Democratic candidate is more experienced), then individuals may vote for the Democrat candidate, even though their positions are closer to the Republican national platform. The reverse is true for $\triangle E X P_{j t+1}<0$.

This voting rule, implies that the vote share obtained by the Democrat in district $j$ at election $t+1$ is

$$
V S_{j t+1}=\Phi\left(\gamma \Delta E X P_{j t+1}-\frac{\delta_{t+1}+\rho_{t+1}}{2}+a_{j t+1}\right) .
$$

$V S_{j t+1}$ and $\triangle E X P_{j t+1}$ is directly observable from the available election returns data. Taking the inverse normal cdf transformation of the vote share yields a structural equation

$$
\Phi_{j t+1}^{-1}=\Phi^{-1}\left(V S_{j t+1}\right)=\gamma \Delta E X P_{j t+1}-\frac{\delta_{t+1}+\rho_{t+1}}{2}+a_{j t+1} .
$$

\subsection{Candidates}

I do not specifically model the candidates decision to run, and the process by which they become candidates. Thus, the econometric framework is robust to various specifications about that particular part of the process. The important point is that the decisions of the candidates of election $t$ to run in election $t+1$ will directly affect the value of $\Delta E X P_{j t+1}$. For example, if the incumbent is a Democrat and both she and her Republican challenger from election $t$ choose to run against each other again, then $\Delta E X P_{j t+1}=\Delta E X P_{j t}+1$. If the Republican retires, and is replaced by a more inexperienced candidate, then the political experience differential will be greater than $\Delta E X P_{j t}+1$. 


\subsection{Identification}

Consider estimating the following ratio, with $e$ very small:

$$
\frac{E\left[\Phi_{j t+1}^{-1} \mid V S_{j t}=\frac{1}{2}+e\right]-E\left[\Phi_{j t+1}^{-1} \mid V S_{j t}=\frac{1}{2}-e\right]}{E\left[\Delta E X P_{j t+1} \mid V S_{j t}=\frac{1}{2}+e\right]-E\left[\Delta E X P_{j t+1} \mid V S_{j t}=\frac{1}{2}-e\right]}
$$

The numerator is simply the average difference in the transformed Democratic vote share in election $t+1$, between bare winners and bare losers in election $t$. The denominator is the average Democratic political experience advantage in election $t+1$, between those winners and losers in

$t$.

It is possible to show that this ratio equals $\gamma$, the structural parameter of interest, as long as

$$
E\left[-\frac{\delta_{t+1}+\rho_{t+1}}{2}+a_{j t+1} \mid V S_{j t}=\frac{1}{2}+e\right]-E\left[-\frac{\delta_{t+1}+\rho_{t+1}}{2}+a_{j t+1} \mid V S_{j t}=\frac{1}{2}-e\right]
$$

approaches zero as $e$ gets arbitrarily small. This will be true if $E\left[a_{j t+1} \mid V S_{j t}\right]$ is continuous at $V S_{j t}=\frac{1}{2}-$ in other words, if the outcome of election $t$ does not affect preferences $a_{j t+1}$, which has been assumed to be exogenous. ${ }^{26}$

Intuitively, $\gamma$ is identified by taking the ratio of two causal effects: 1) the effect of a Democratic victory in $t$ on (a monotonic transformation of) the Democratic vote share in $t+1$ (which, by assumption, operates through the voters' valuation of experience) and 2) the effect of a Democratic victory in $t$ on the Democratic experience advantage in election $t+1$. Each of these causal effects can be estimated using the same procedure described in Section 4

\section{Structural Estimates and Alternative Estimation Approaches}

Figures VIa and VIb empirically illustrate the inputs used to estimate the structural parameter $\gamma$. Figure VIa plots the empirical relationship between the Democratic experience advantage

\footnotetext{
26 The importance of assuming a national party platform is apparent here. If we allowed for district-specific platforms, we might also suspect that they could be affected by the outcome of the previous election; in that case, we could not distinguish between voters' valuation of experience and the voters' voting in favor of the incumbent because they put forth platforms that are more popular.
} 
in $t+1$ and the vote share margin of victory in election $t .{ }^{27}$ The data once again produce a striking jump at the 0 threshold, implying that a Democratic win in $t$ causes an experience differential of about 2.8 congressional terms in favor of the Democratic party in $t+1$. We know that if all candidates never "dropped out", the gap would be exactly 2 . The larger gap suggests that losing Democrats (as well as the losing opposition to winning Democrats) are dropping out and being replaced by less experienced candidates.

The discontinuous jump apparent in Figure VIb represents a causal effect of a Democratic win in $t$ on the (inverse normal cdf transformation of) the Democratic vote share in $t+1 .{ }^{28}$ By the institutional and behavioral assumptions of the model, the only reason for this causal relationship is through the effect of Democratic victory on the $t+1$ experience differential.

The top panel of Table $\mathrm{V}$ reports the results from the estimation of the structural model. In the first entry of Column (1), I estimate the "first-stage" causal effect of a Democratic win in $t$ on $\triangle E X P_{j t+1}$. The estimate of the denominator in Equation 11 (and the size of the discontinuity jump in Figure VIa) is 2.832. The estimate of the numerator in Equation 11 (and the size of the discontinuity jump in Figure VIb) is 0.208 . The ratio of these values is the estimate of $\gamma$, which is 0.073 , highly statistically significant. ${ }^{29}$ This estimate implies that an additional Congressional term of experience (over the opposing candidate) attracts voters towards that candidate by 0.073 of a standard deviation (in terms of underlying political preferences within a district), a seemingly modest magnitude. However, in close elections, that 0.073 translates to a 2.5 percent vote share difference, which of course can make a significant influence on the eventual outcome.

The deceptively small estimate of $\gamma$ can play a significant role accounting for the persis-

\footnotetext{
27 Local averages are calculated for every 1 percent vote share interval.

28 Since the inverse normal cdf is unbounded, uncontested elections in $t+1$ were necessarily dropped. The polynomial fits use the same 4th order polynomials in the margin of victory (interacted with victory $(t)$ ) as in previous figures.

29 Practically, this is an instrumental variable estimate from regression of the transformed vote share on $\Delta E X P_{j t+1}$ instrumenting with the indicator of a Democratic win in $t$, using the 4th order polynomial in the margin of the victory (and the interaction of these terms with the win indicator) as covariates.
} 
tently high electoral success of incumbents in the U.S. House. I use my estimate of $\gamma$ to ask what would the incumbent party re-election rate be if all $\Delta E X P_{j t+1}$ were set to zero. This would correspond to the extreme policy of mandatory term limits of 1 , where in each election, no candidate has an experience advantage. Adjusting the actual vote shares by $\widehat{\gamma} \Delta E X P_{j t+1}$ and tallying up the counterfactual electoral outcomes yields a dramatic impact. The electoral success of the incumbent party falls from about 90 percent to 60 percent, and the electoral success of the non-incumbent party rises from about 10 percent to 40 percent. Approximately two-thirds of the observed electoral success can be explained by the existing distribution of experience differences between candidates for the U.S. House. This makes some intuitive sense, since we know (Table II) that the average political experience difference is more than 3 and a half terms of experience. The average difference between the simulated and actual vote shares is about 10 percent, a significant political magnitude.

Finally, the bottom panel of Table V reports the estimates of the structural parameter under alternative specifications: a heuristic "fixed effects" and an alternative "instrumental variable" approach to modeling the unobservables. An attractive feature of a research design where there is arguably not only exogenous but also as good as random variation in the "treatment" variable, is that it provides a baseline for assessing whether or not other commonly-used econometric approaches would yield the same "experimental" estimate. ${ }^{30}$ Since "fixed effects" and "instrumental variable" approaches implicitly assume continuity of the distribution of unobservables, the typical assumptions used in "differencing" and IV approaches are necessarily more restrictive than the mild stochastic assumptions invoked in Section 5. Thus, substantial deviation of the alternative estimates from the baseline results of Table $\mathrm{V}$ would be an indication that the assumptions required

\footnotetext{
30 This is the spirit of the influential work of Lalonde [1986]. Obviously, the situation here is not literally a controlled, true "experiment". However, in a sense, there is as much evidence that this is as good as a randomized experiment as there is, for example, that the NSW program was correctly randomized in Lalonde [1986]. This was the point of showing Table II, which is analogous to Lalonde's Table I that provides empirical evidence that the randomization "worked".
} 
for "fixed effects" and other "IV" approaches are invalid in this particular context.

Table V show that these estimates indeed depart substantially from the quasi-experimental estimates. A "fixed-effect" regression yields an estimate of 0.022 , which is less than a third of the magnitude of the baseline regression discontinuity estimate of $\gamma \cdot{ }^{31}$ The fixed effects assumption which considers 10 and assumes that $a_{j t+1}=a_{j t}$ - appears to be inappropriate in this context.

Suppose the econometrician were to utilize the assumed exclusion restriction that a Democratic victory does not directly and independently impact the electoral outcome in $t+1$ except through $\triangle E X P_{j t+1}$. But suppose the analyst were to conjecture that there was "no reason to believe that a Democratic victory should be correlated with $a_{j t+1} .{ }^{.32}$ These assumptions would suggest an IV estimator that does not control for a non-parametric function of the margin of victory at $t .{ }^{33}$ This analyst would obtain misleading inferences regarding $\gamma$, as shown by the last row of estimates in Table V. This "instrumental variable" approach yields estimates that are about 50 percent too high.

In this particular application, the best estimate is in fact the simplest cross-sectional OLS regression, which yields an estimate of about 0.06 for $\gamma$. The specification is a regression of the transformed vote share on $\Delta E X P_{j t+1}$ and a set of year dummies. ${ }^{34}$ On the other hand, both the OLS and alternative IV estimates give misleading inferences concerning whether $\gamma$ varies by subgroups defined by $\triangle E X P_{j t}$. They imply that the $\gamma$ declines with a higher initial $\Delta E X P_{j t}$, when in fact, as the top panel of Table V demonstrates, the interaction effects are statistically insignificant.

31 This "differencing" specification is a regression of the the transformed vote share on a set of year dummies (to presumably "absorb" the $\frac{\delta_{t}-\rho_{t}}{2}$ term), state-district-decade dummies (that presumably "absorbs" the "permanent heterogeneity" in $a_{j t}$; i.e. the assumption is that $a_{j t^{\prime}}=a_{j t^{\prime \prime}}$ for all $t^{\prime}$ and $t^{\prime \prime}$ within a decade), and $\Delta E X P_{j t+1}$.

32 Actually, given the setup of the model, there are a lot of reasons to expect that the Democrat win variable should be correlated with $a_{j t+1}$. Namely, a simple autocorrelation of $a_{j t}$ would produce such a correlation.

33 Specifically, the regression is the transformed vote share on $\Delta E X P_{j t+1}$ using the Democratic victory indicator in election $t$ as an instrument, and including year dummies as the covariates.

34 This "cross-sectional OLS" specification should not be confused with the naive comparison of means that were presented in Table II. Here we are examining the relationship between electoral outcomes and the experience differential. 
The regression discontinuity estimates indicate that the null hypothesis of homogeneity along this dimension cannot be rejected.

\section{Conclusions}

This paper exploits the "near"-random assignment of incumbency generated by close U.S. House elections in order to 1) assess whether or not the electoral success of incumbents is a mere artifact of selection, 2) quantify the reduced-form causal relationship of incumbency on subsequent electoral outcomes, 3) provide an input - arguably free of selection bias - to a structural model of voting behavior that produces an estimate of the voter's valuation of political experience, and 4) to evaluate the performance of commonly-used alternative approaches to modelling the unobservables within this context.

I find evidence that rejects the pure spurious-selection hypothesis, and estimate that incumbency has a significant positive causal effect on the probability that the incumbent candidate or party will run again for office and succeed, by about 0.40 to 0.45 . Losing candidates most often do not run again for election, and while much of this is due to selection, a significant portion of this represents a causal relationship. A structural model implies that heterogeneity in political preferences across voters (within district) is quite large, relative to the implicit valuation of congressional experience, but that even this modest valuation can be important. According to the model, about two-thirds of the apparent electoral success of incumbents can be attributed to the distribution of political experience differences across Congressional districts in the U.S. Finally, the results suggest that an analyst relying on a "fixed effect" approach to estimating the valuation of experience would obtain a significantly downward-biased estimated. They also suggest that an analyst employing "IV" by relying on the assumed exclusion restriction - but simply asserting orthogonality of the instrument and the unobservable error term - would generate seriously upwardly-biased 
estimates in this particular context.

Meaningful theories of political agency ultimately make causal empirical predictions. If there is any hope in assessing whether any or which of these theories have empirical relevance, it lies in evaluating whether or not there is definitive evidence that these causal relationships actually reveal themselves in real-world data. Unobservable selection and omitted-variable bias is endemic in empirical research, so such definitive evidence is likely to be quite rare; unilaterally relying on a particular approach (e.g. "differencing" or "IV") for modelling unobservable mechanisms has the potential for producing misleading inferences. By contrast, it appears that examining the "near"experiment generated by close elections may be a promising approach in this line of research. 


\section{Data Appendix}

The data used for this analysis is based on the candidate-level Congressional election returns for the U.S., from ICPSR study 7757, "Candidate and Constituency Statistics of Elections in the United States, 1788-1990".

The data were initially checked for internal consistencies (e.g. candidates' vote totals not equalling reported total vote cast), and corrected using published and official sources (Congressional Quarterly [1997] and the United States House of Representatives Office of the Clerk's Web Page). Election returns from 1992-1998 were taken from the United States House of Representatives Office of the Clerk's Web Page, and appended to these data. Various states (e.g. Arkansas, Louisiana, Florida, and Oklahoma) have laws that do not require the reporting of candidate vote totals if the candidate ran unopposed. If they are the only candidate in the district, they were assigned a vote share of 1 . Other individual missing vote totals were replaced with valid totals from published and official sources. Individuals with more than one observation in a district year (e.g. separate Liberal and Democrat vote totals for the same person in New York and Connecticut) were given the total of the votes, and were assigned to the party that gave the candidate the most votes. The name of the candidate was parsed into last name, first name, and middle names, and suffixes such as “Jr., Sr., II, III, etc.”

Since the exact spelling of the name differs across years, the following algorithm was used to create a unique identifier for an individual that could match the person over time. Individuals were first matched on state, first 5 characters of the last name, and first initial of the first name. The second layer of the matching process isolates those with a suffix such as Jr. or Sr., and small number of cases were hand-modified using published and official sources. This algorithm was checked by drawing a random sample of 100 election-year-candidate observations from the original sample, 
tracking down every separate election the individual ran in (using published and official sources; this expanded the random sample to 517 election-year-candidate observations), and asking how well the automatic algorithm performed. The fraction of observations from this "truth" sample that matched with the processed data was 0.982 . The fraction of the processed data for which there was a "true" match was 0.992. Many different algorithms were tried, but the algorithm above performed best based on the random sample.

Throughout the sample period (1946-1998), in about 3 percent of the total possible number of elections (based on the number of seats in the House in each year), no candidate was reported for the election. I impute the missing values using the following algorithm. Assign the state-year average electoral outcome; if still missing, assign the state-decade average electoral outcome.

Two main data sets are constructed for the analysis. For all analysis at the Congressional level, I keep all years that do not end in ' 0 ' or ' 2 '. This is because, strictly speaking, Congressional districts cannot be matched between those years, due to decennial re-districting, and so in those years, the previous or next electoral outcome is undefined. The final data set has 6558 observations. For the analysis at the individual candidate level, one can use more years, because, despite redistricting, it is still possible to know if a candidate ran in some election, as well as the outcome. This larger dataset has 9674 Democrat observations.

For the sake of conciseness, the empirical analysis in the paper focuses on observations for Democrats only. This is done to avoid the "double-counting" of observations, since in a largely two-party context, a winning Democrat will, by construction, produce a losing Republican in that district and vice versa. (It is unattractive to compare a close winner to the closer loser in the same district) In reality, there are third-party candidates, so a parallel analysis done by focusing on Republican candidates will not give a literal mirror image of the results. However, since thirdparty candidates tend not to be important in the U.S. context, it turns out that all of the results are 
qualitatively the same, and are available from the author upon request. 


\section{References}

[1] Alesina, Alberto, and Howard Rosenthal. "Partisan Cycles in Congressional Elections and the Macroeconomy." American Political Science Review 83 (1989): 373-398.

[2] Alford, John R., and John R. Hibbing. "Increased Incumbency Advantage in the House." Journal of Politics 43 (1981): 1042-61.

[3] Angrist, Joshua D., and Victor Lavy. "Using Maimondies' Rule to Estimate the Effect of Class Size on Scholastic Achievement." Quarterly Journal of Economics 114 (1998):533-75.

[4] Austen-Smith, David, and Jeffrey Banks. "Electoral Accountability and Incumbency." in Models of Strategic Choice in Politics, Peter C. Ordeshook, ed. Ann Arbor, Michigan: University of Michigan Press, 1989.

[5] Baron, David P. "Service-induced Campaign Contributions and the Electoral Equilibrium." Quarterly Journal of Economics 104 (1989): 45-72.

[6] Besley Timothy, and Anne Case. "Does Electoral Accountability Affect Economic Policy Choices? Evidence from Gubernatorial Term Limits." Quarterly Journal of Economics 110 (1995): 769-798.

[7] Besley Timothy, and Anne Case. "Incumbent Behavior: Vote-Seeking, Tax-Setting, and Yardstick Competition." American Economic Review 85 (1995): 25-45.

[8] Campbell, D. T. "Reforms as Experiments." American Psychologist 24 (1969): 409-29.

[9] Collie, Melissa P. "Incumbency, Electoral Safety, and Turnover in the House of Representatives, 1952-1976." American Political Science Review 75 (1981): 119-31.

[10] Congressional Quarterly. Congressional Elections: 1946-1996. 1997.

[11] Erikson, Robert S. "The Advantage of Incumbency in Congressional Elections." Polity 3 (1971): 395-405.

[12] Fan, J., and I. Gijbels. Local Polynomial Modelling and Its Applications, New York, New York: Chapman and Hall, 1996.

[13] Garand, James C., and Donald A. Gross. "Change in the Vote Margins for Congressional Candidates: A Specification of the Historical Trends." American Political Science Review 78 (1984): 17-30.

[14] Gelman, Andrew, and Gary King. "Estimating Incumbency Advantage without Bias." American Journal of Political Science 34 (1990): 1142-64.

[15] Gronau, R. "Leisure, home production and work - the theory of the allocation of time revisited." Journal of Political Economy 85 (1977): 1099-1124.

[16] Grossman Gene M., and Elhanan Helpman. "Electoral Competition and Special Interest Politics." Review of Economic Studies 63 (1996): 265-286.

[17] Hahn, Jinyong, Petra Todd, and Wilbert van der Klaauw. "Identification and Estimation of Treatment Effects with a Regression-Discontinuity Design." Econometrica 69 (2001): 201209.

[18] Heckman, James J. "Dummy Endogenous Variables in a Simultaneous Equations System." Econometrica 46 (1978): 931-59.

[19] Heckman, James J. “Sample selection bias as a specification error.” Econometrica 47 (1979): $153-62$.

[20] Inter-university Consortium for Political and Social Research. "Candidate and Constituency 
Statistics of Elections in the United States, 1788-1990" Computer File 5th ICPSR ed. Ann Arbor, MI: Inter-university Consortium for Political and Social Research, producer and distributor, 1995.

[21] Jacobson, Gary C. "The Marginals Never Vanished: Incumbency and Competition in Elections to the U.S. House of Representatives.” American Journal of Political Science 31 (1987): 12641.

[22] Jacobson, Gary C. The Politics of Congressional Elections, Menlo Park, California: Longman, 1997.

[23] Kalt, Joseph P., and Mark A. Zupan. "Capture and Ideology in the Economic Theory of Politics." American Economic Review 74 (1984): 279-300.

[24] Lalonde, Robert J. "Evaluating the Econometric Evaluations of Training Programs with Experimental Data." American Economic Review 76 (1986): 604-620.

[25] Levitt, Steven D. "Using Repeat Challengers to Estimate the Effect of Campaign Spending on Election Outcomes in the U.S. House.” Journal of Political Economy 102 (1994): 777-798.

[26] Levitt, Steven D., and James M. Poterba. "Congressional Distributive Politics and State Economic Performance.” NBER Working Paper \#4721 (1994).

[27] Levitt, Steven D. "How Do Senators Vote? Disentangling the Role of Voter Preferences, Party Affiliation, and Senator Ideology." American Economic Review 86 (1996): 425-441.

[28] Levitt, Steven D., and Catherine D. Wolfram. "Decomposing the Sources of Incumbency Advantage in the U.S. House.” Legislative Studies Quarterly 22 (1997) 45-60.

[29] Payne, James L. "The Personal Electoral Advantage of House Incumbents." American Politics Quarterly 8 (1980): 375-98.

[30] Peltzman, Sam. "Constituent Interest and Congressional Voting." Journal of Law and Economics 27 (1984): 181-210.

[31] Peltzman, Sam. "An Economic Interpretation of the History of Congressional Voting in the Twentieth Century." American Economic Review 75 (1985): 656-675.

[32] Rogoff, Kenneth. "Equilibrium Political Budget Cycles.” American Economic Review 80 (1990): 21-36.

[33] Rogoff, Kenneth, and Anne Sibert. "Elections and Macroeconomic Policy Cycles" Review of Economic Studies 55 (1988): 1-16.

[34] Snyder, James M. "Campaign Contributions as Investments: The U.S. House of Representatives, 1980-1986." Journal of Political Economy 98 (1990): 1195-1227.

[35] Thistlethwaite, D., and D. Campbell. "Regression -Discontinuity Analysis: An alternative to the ex post facto experiment." Journal of Educational Psychology 51 (1960): 309-17.

[36] Van der Klaauw, Wilbert. "Estimating the Effect of Financial Aid Offers on College Enrollment: A Regression-Discontinuity Approach.” Unpublished manuscript (1996). 


\section{FIGURE I: Electoral Success of U.S. House Incumbents:}

1948-1998

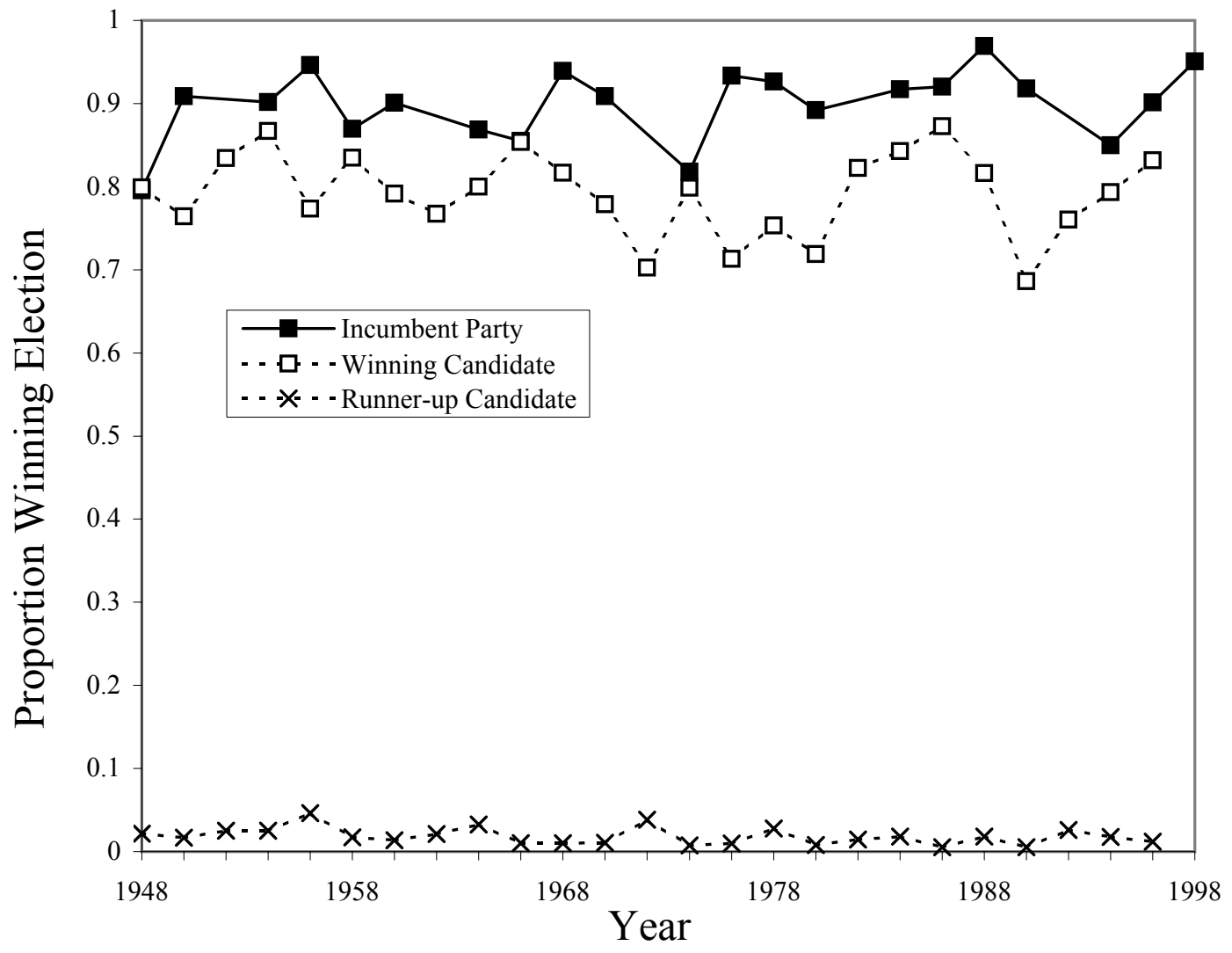

Note: Calculated from ICPSR study 7757. Details in Data Appendix. Incumbent party is the party that won the election in the preceding election in that congressional district. Due to re-districting on years that end with "2", there are no points on those years. Other series are the fraction of individual candidates in that year, who win an election in the following period, for both winners and runner-up candidates of that year. 
Figure IIa: Candidate's Probability of Winning Election $t+1$, by

Margin of Victory in Election t: local averages and parametric fit

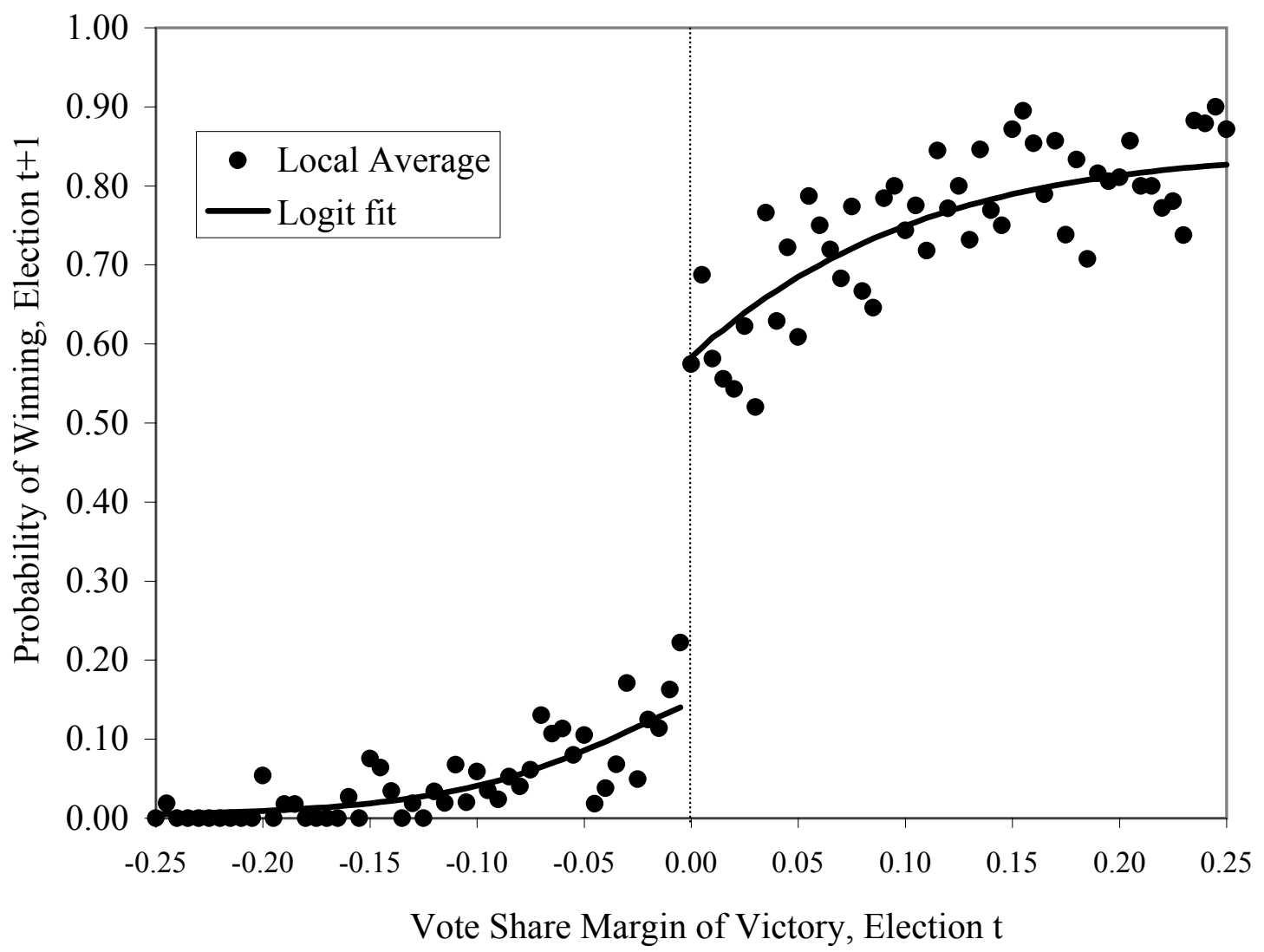

Figure IIb: Candidate's Accumulated Number of Past Election Victories, by Margin of Victory in Election t: local averages and parametric fit

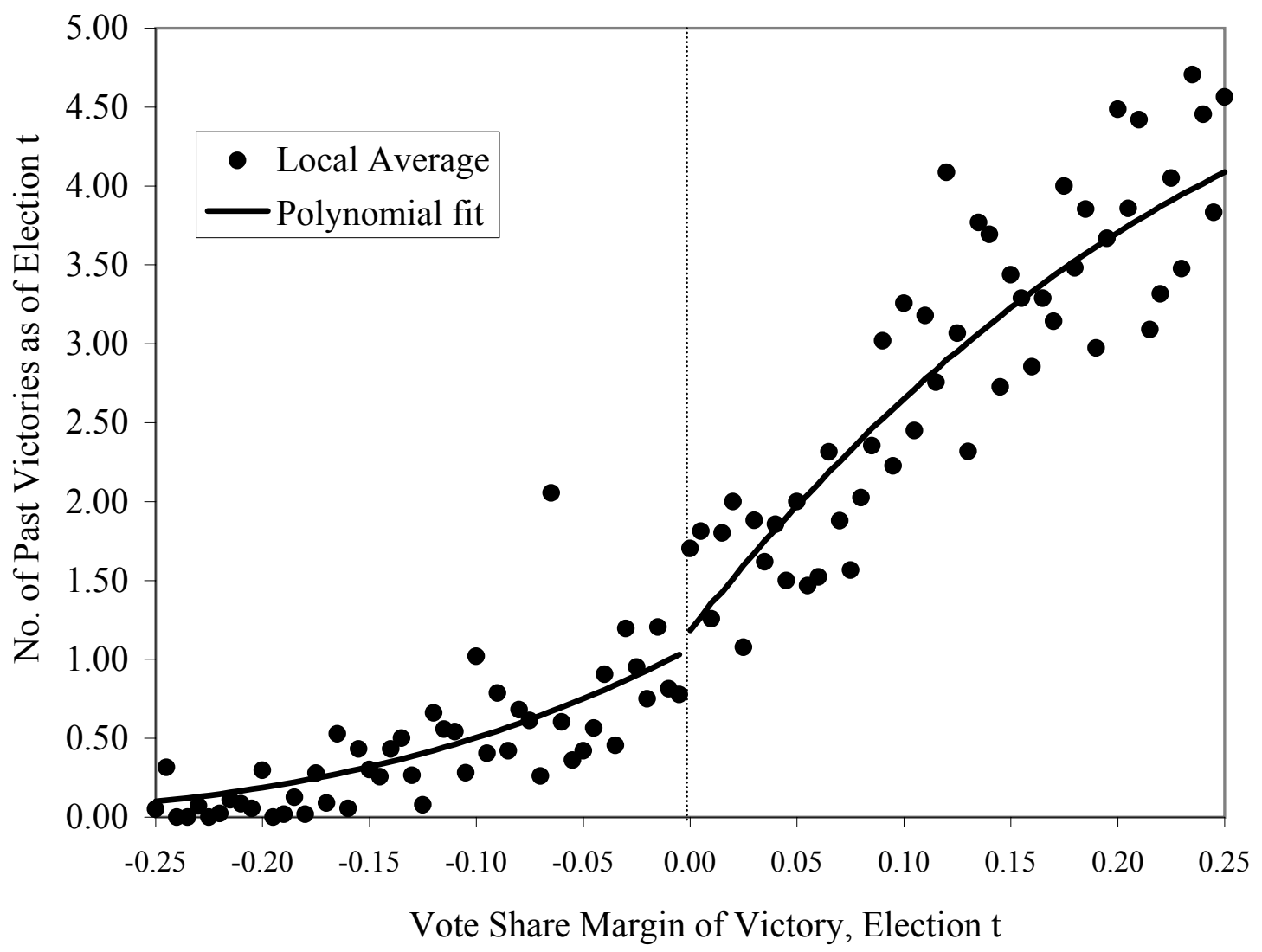


Figure IIIa: Candidate's Probability of Candidacy in Election $\mathbf{t}+\mathbf{1}$, by Margin of Victory in Election t: local averages and parametric fit

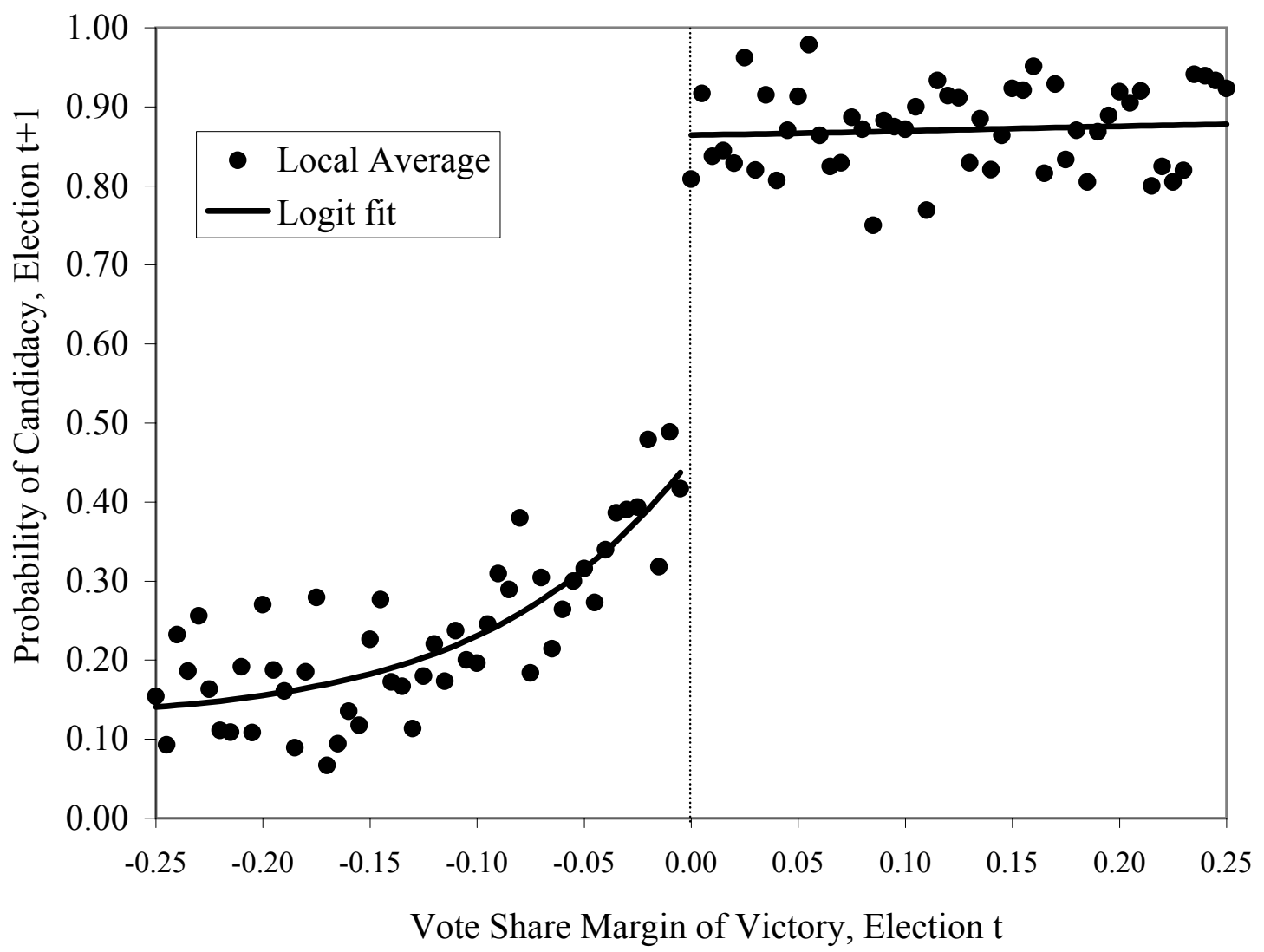

Figure IIIb: Candidate's Accumulated Number of Past Election Attempts, by Margin of Victory in Election t: local averages and parametric fit

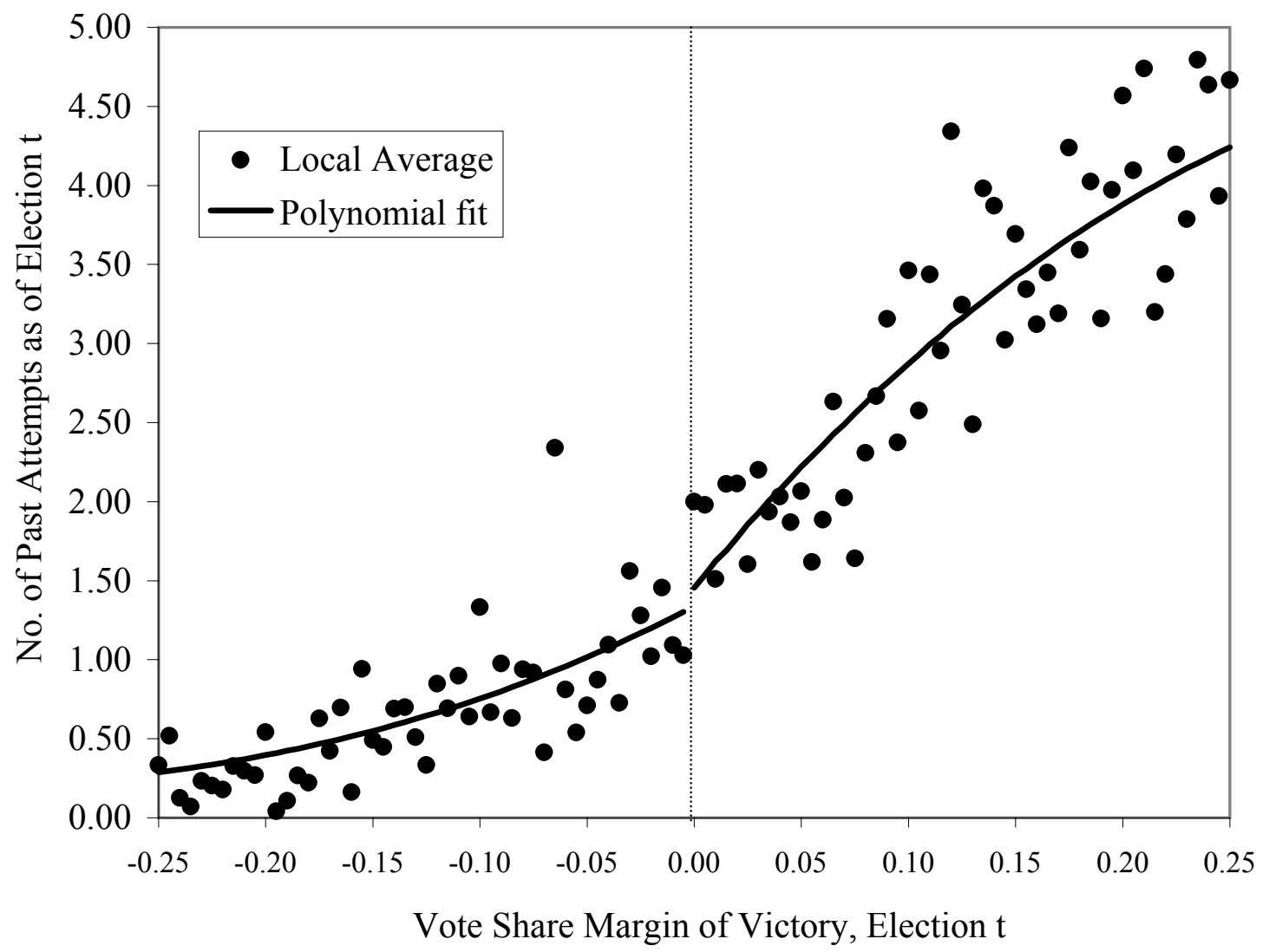


Figure IVa: Democrat Party's Vote Share in Election t+1, by

Margin of Victory in Election t: local averages and parametric fit

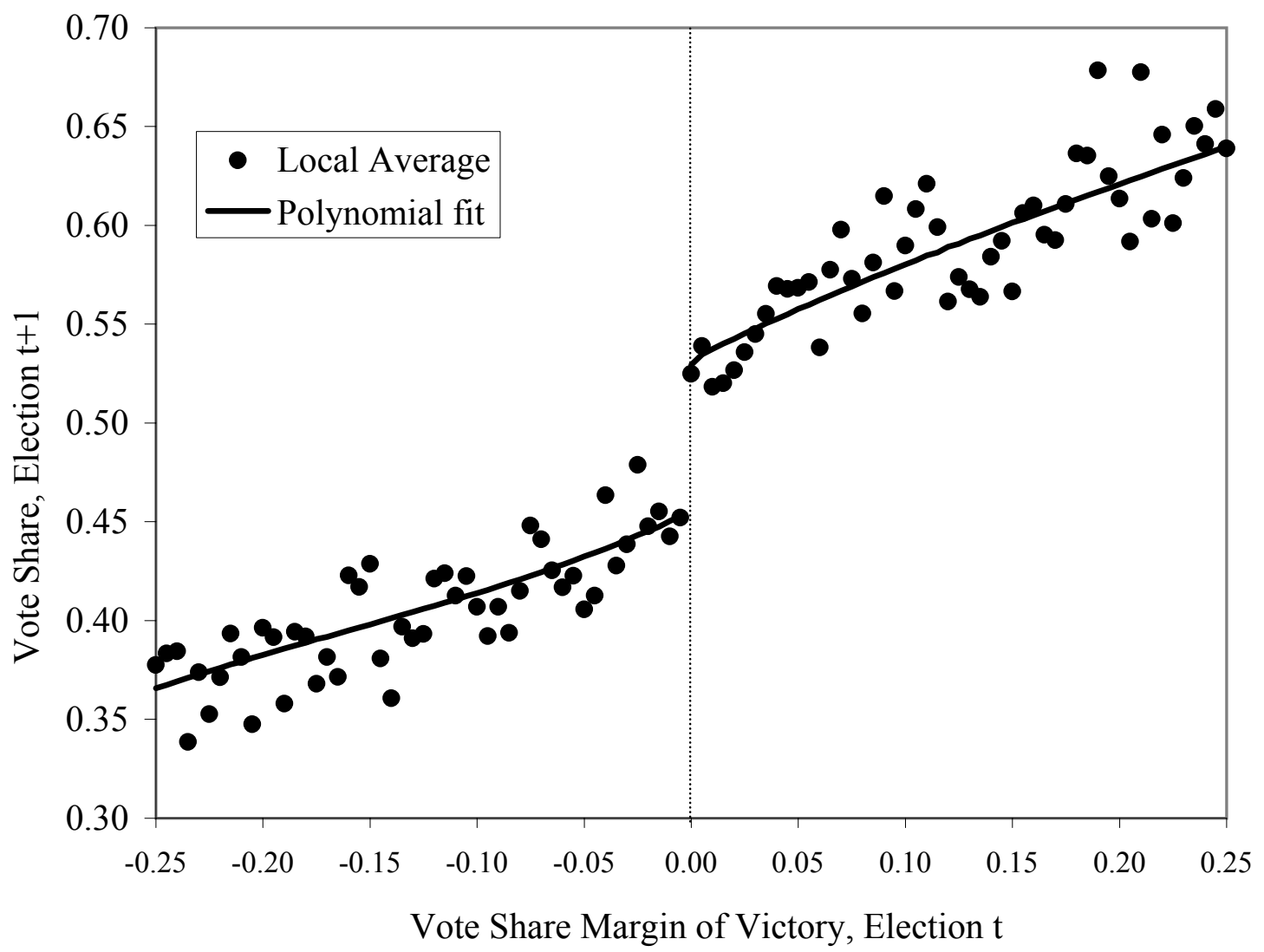

Figure IVb: Democratic Party Vote Share in Election t-1, by Margin of Victory in Election t: local averages and parametric fit

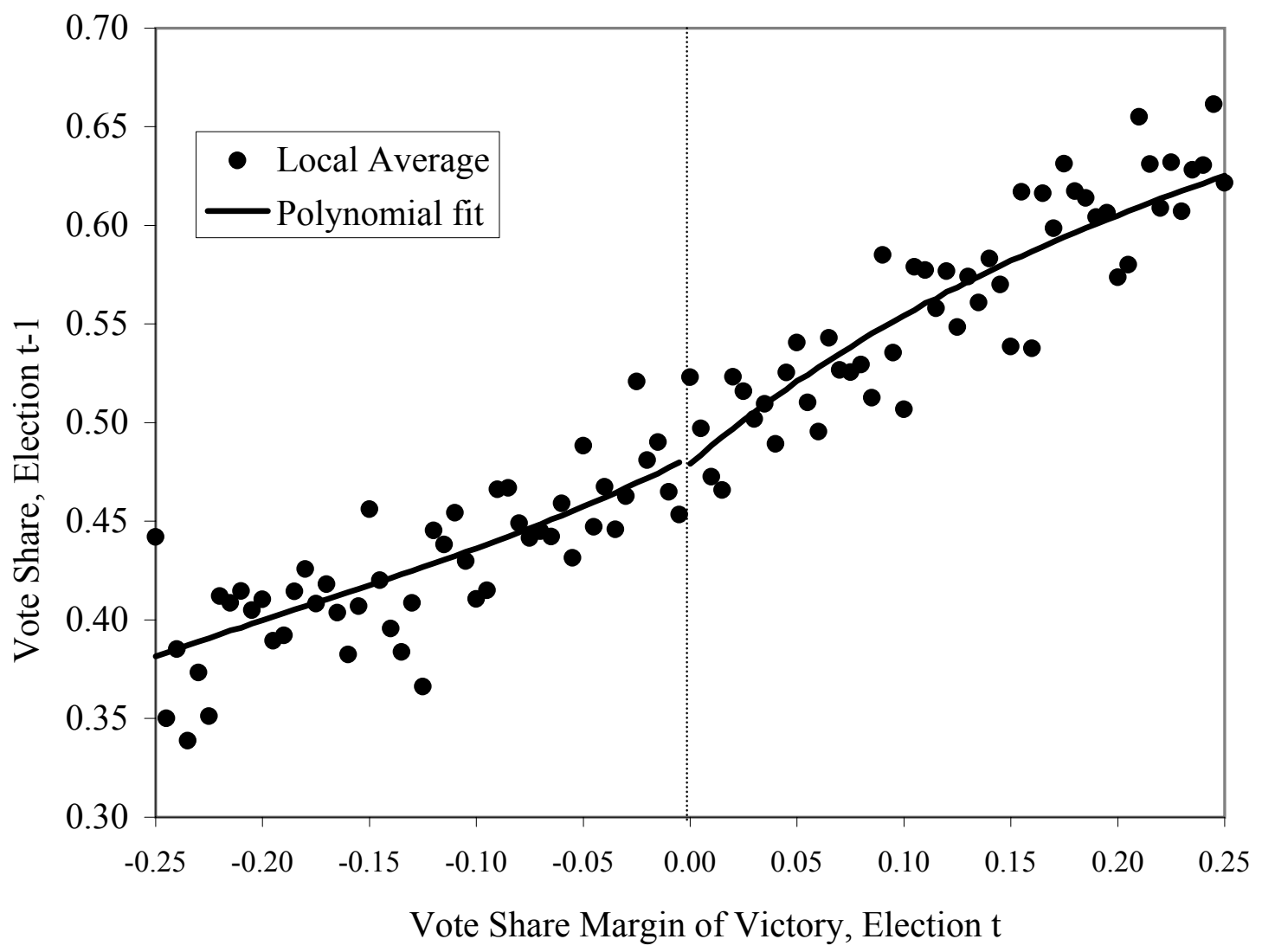


Figure Va: Democratic Party Probability Victory in Election $t+1$, by Margin of Victory in Election t: local averages and parametric fit

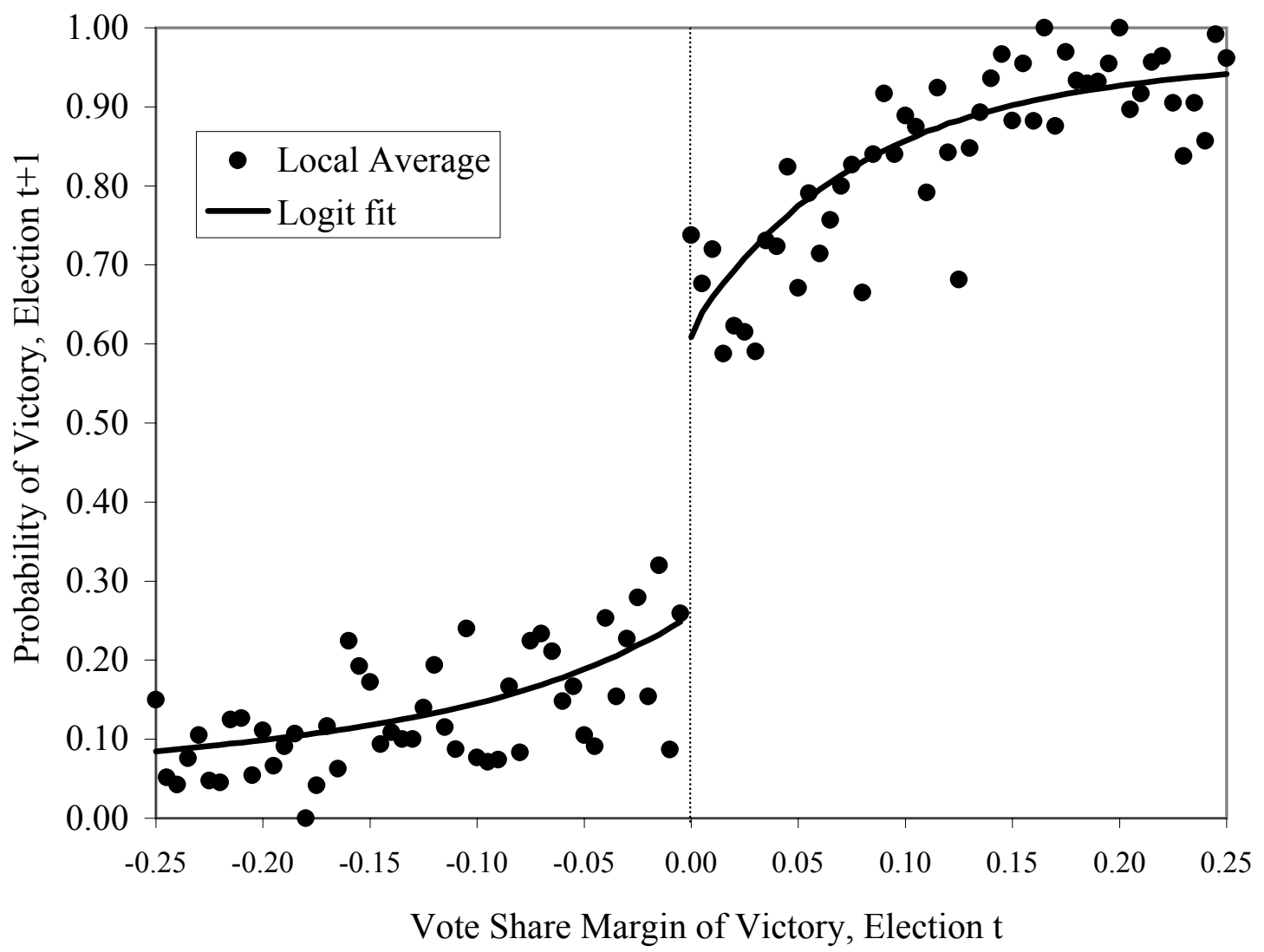

Figure Vb: Democratic Probability of Victory in Election t-1, by Margin of Victory in Election t: local averages and parametric fit

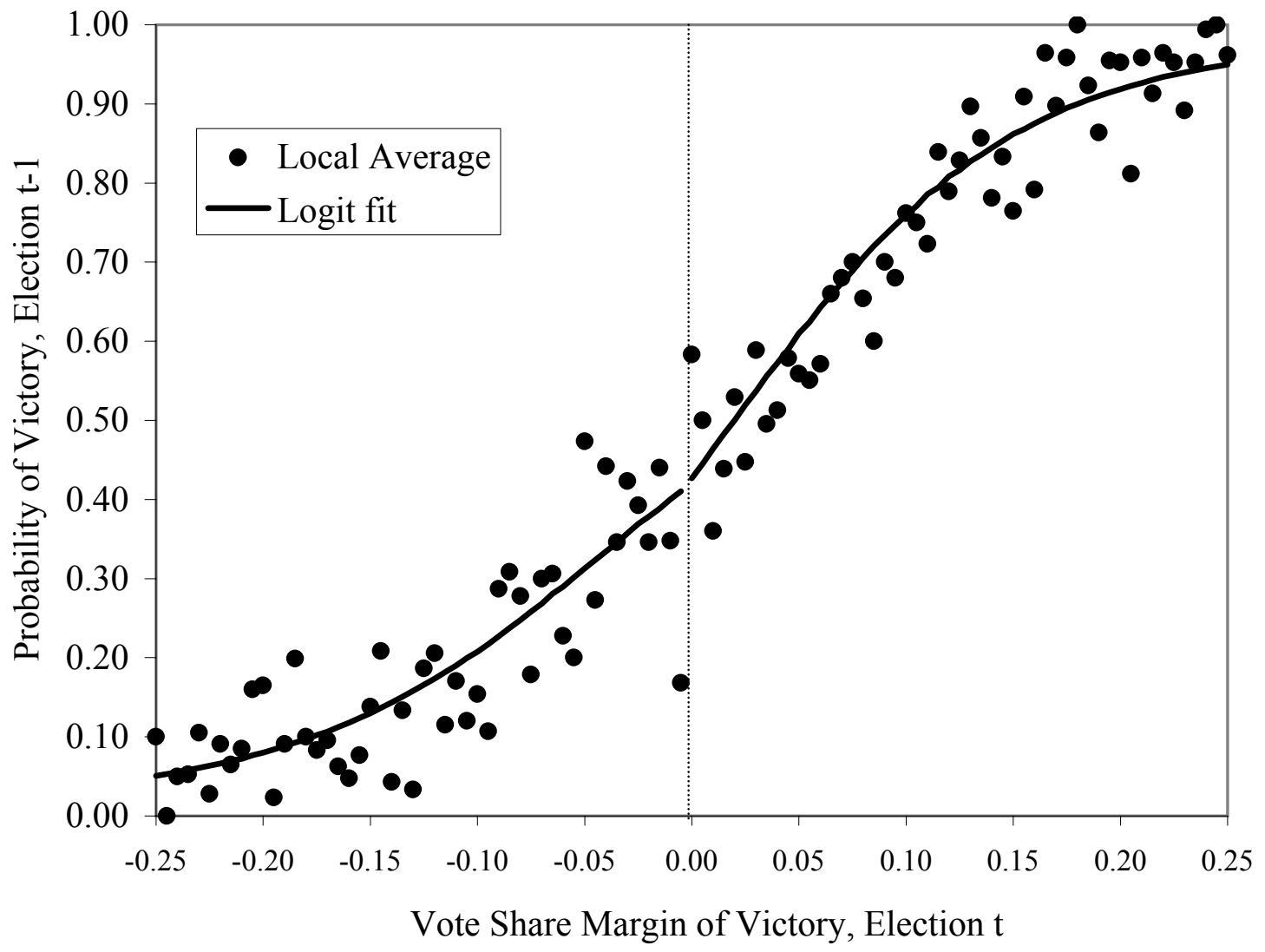


Figure VIa: Effect of Election Victory (t) on Political Experience Differential $(\mathbf{t}+\mathbf{1})$

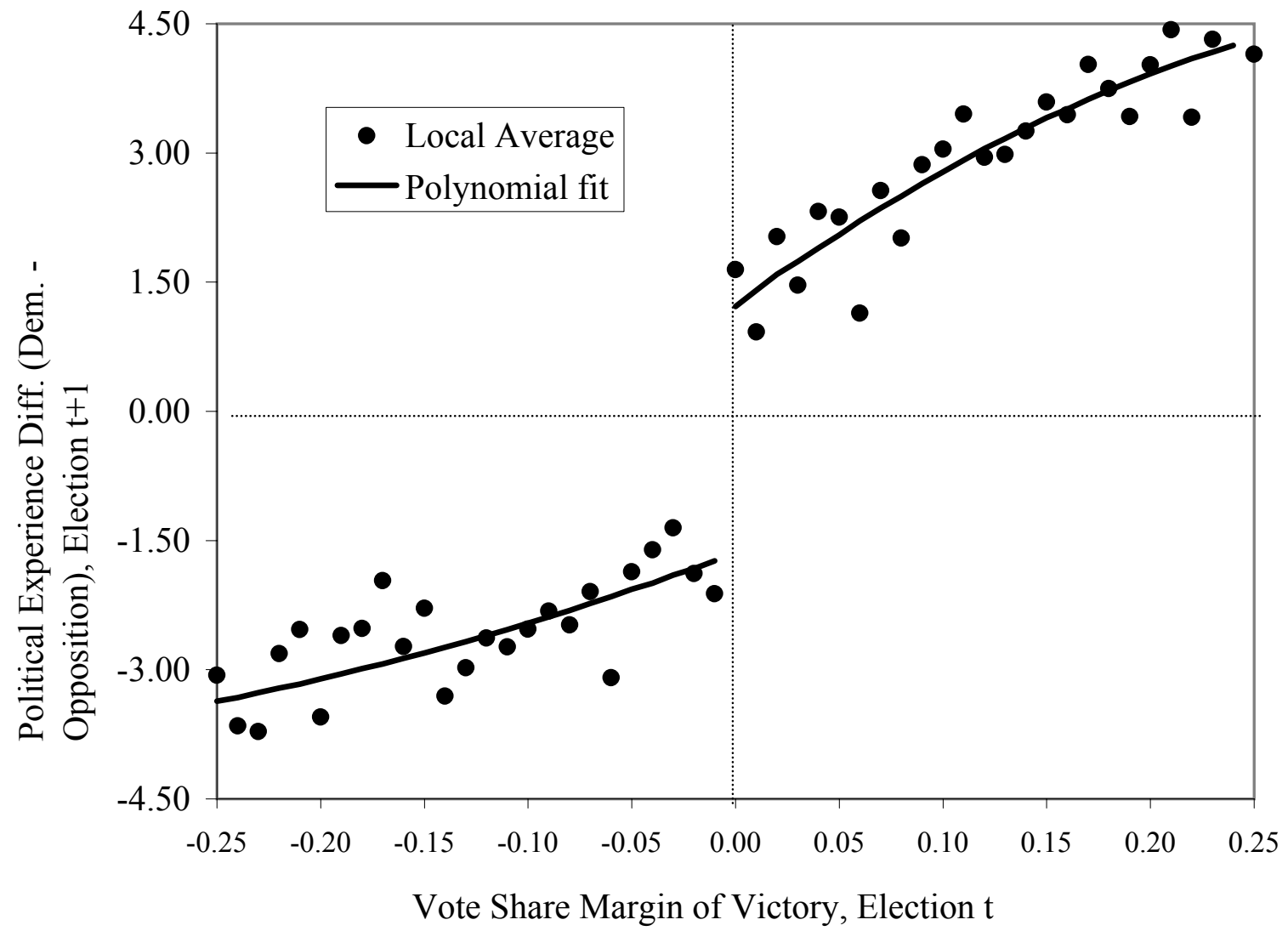

Figure VIb: Effect of Election Victory (t) on Two-party Democratic Vote Share Index $(\mathbf{t}+\mathbf{1})$

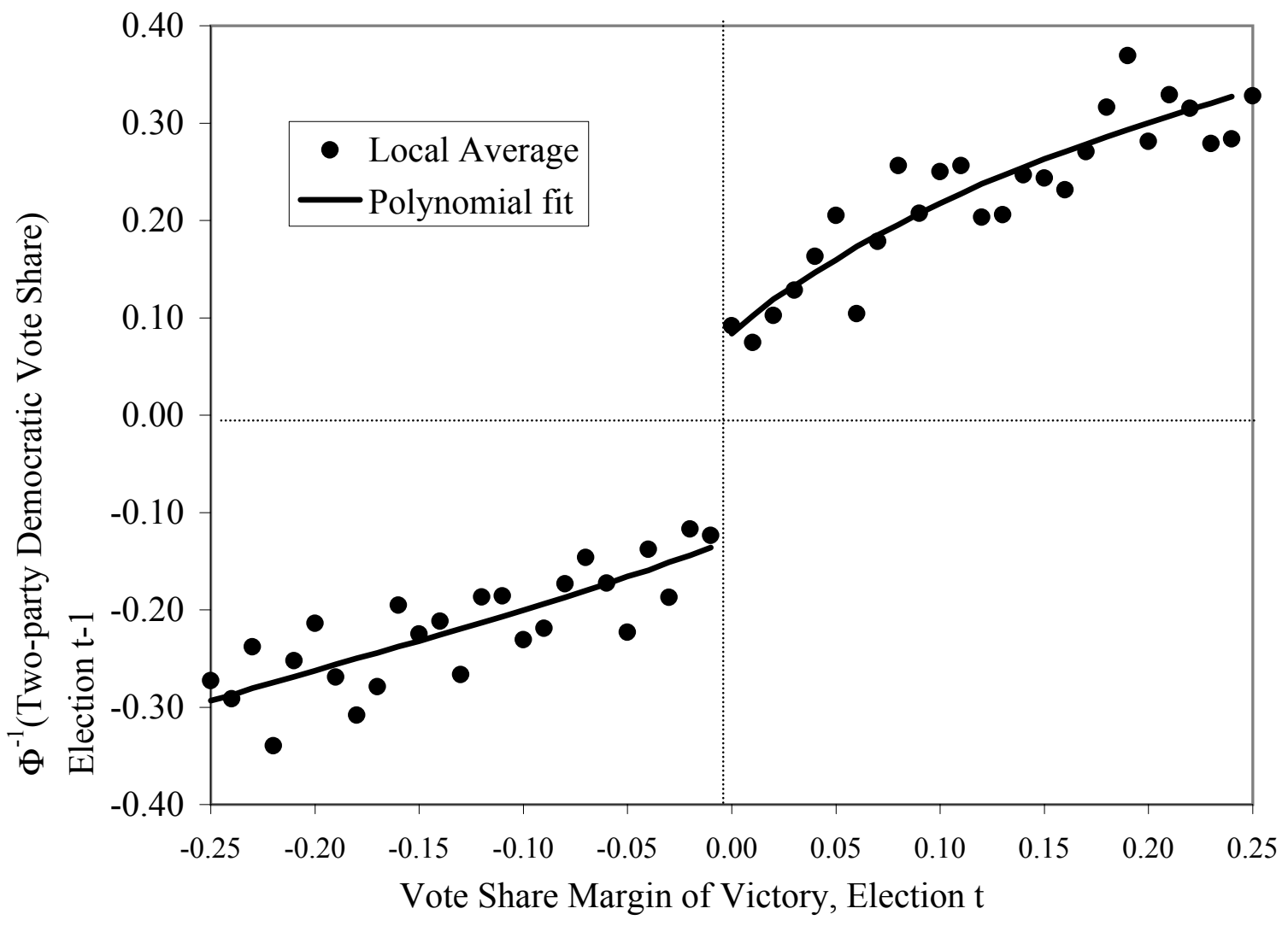


TABLE I: Electoral Outcomes for Democratic Candidates and the Democratic Party, U.S. House of Representatives, 1946-1998

\begin{tabular}{|c|c|c|c|c|}
\hline & $\begin{array}{l}\text { Proportion } \\
\text { Win } \\
\text { Election } t+1\end{array}$ & $\begin{array}{l}\text { Proportion a } \\
\text { Candidate in } \\
\text { Election } t+1\end{array}$ & $\begin{array}{l}\text { No. of Past } \\
\text { Victories } \\
\text { by Election } t\end{array}$ & $\begin{array}{l}\text { No. of times a } \\
\text { Candidate } \\
\text { by Election } t\end{array}$ \\
\hline $\begin{array}{l}\text { Winner of Election } t \\
(t+1 \text { Incumbent })\end{array}$ & 0.803 & 0.875 & 3.798 & 3.925 \\
\hline \multirow[t]{2}{*}{ Runner-up of Election $t$} & 0.025 & 0.186 & 0.270 & 0.479 \\
\hline & \multicolumn{2}{|c|}{$\begin{array}{l}\text { Democratic Vote Share in } \\
\text { Election } t+1\end{array}$} & \multicolumn{2}{|c|}{$\begin{array}{l}\text { Democratic Vote Share in } \\
\text { Election } \mathrm{t}-1\end{array}$} \\
\hline $\begin{array}{l}\text { Winner of Election } t \\
(t+1 \text { Incumbent Party })\end{array}$ & \multicolumn{2}{|l|}{0.702} & \multicolumn{2}{|l|}{0.684} \\
\hline Runner-up of Election $t$ & \multicolumn{2}{|l|}{0.344} & \multicolumn{2}{|l|}{0.366} \\
\hline
\end{tabular}

Note: Calculated from ICPSR study 7757. Details in Data Appendix. Entries are for Democratic candidates only. N=6241, 4326, 3671, and 2688 for the 1st, 2nd, 3rd, and 4th rows, respectively. The third and fourth rows exclude years that end in "2" or " 0 " because, due to redistricting, voteshares in election $\mathrm{t}+1$ and $\mathrm{t}-1$ are not defined for those years. 


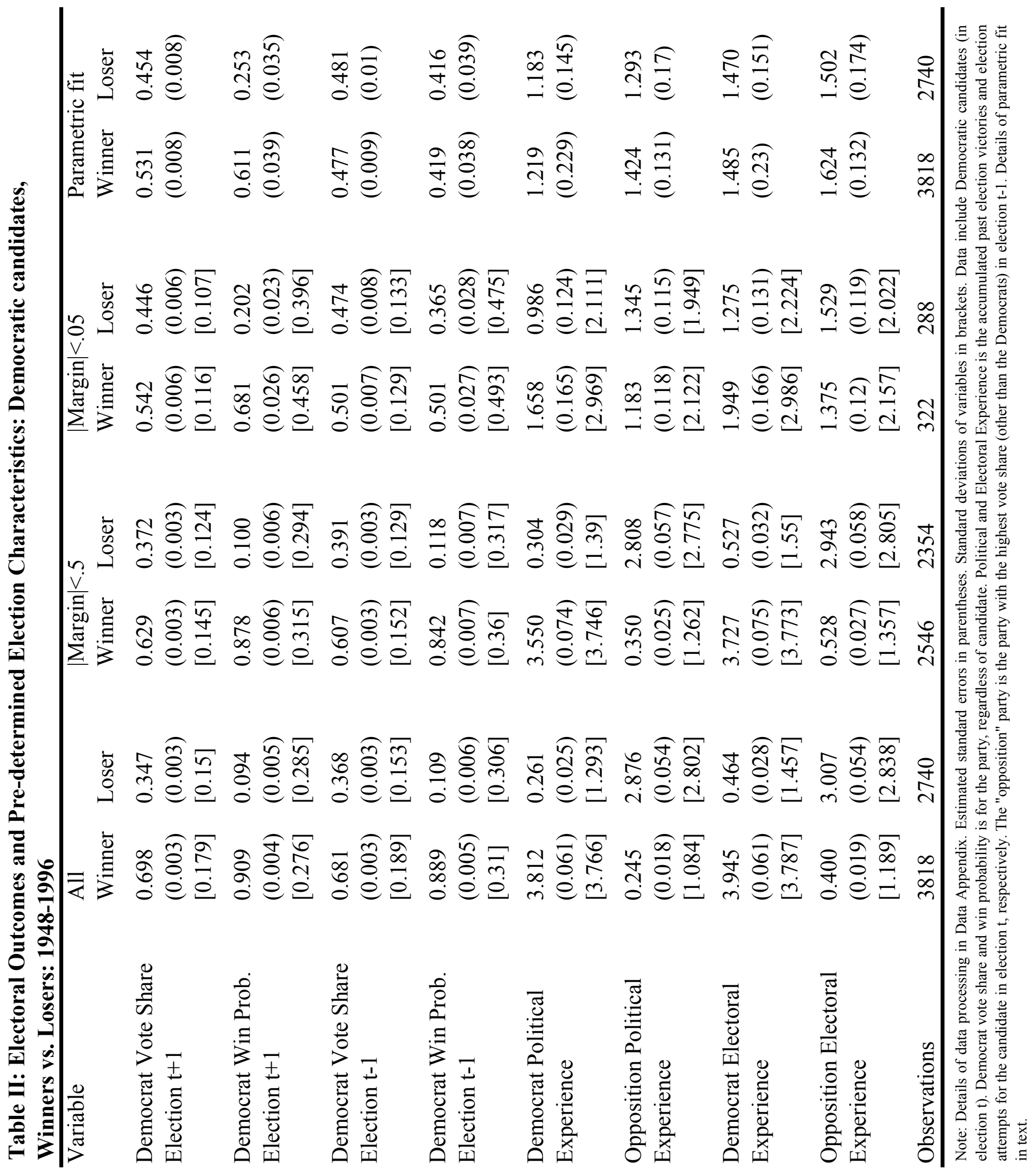




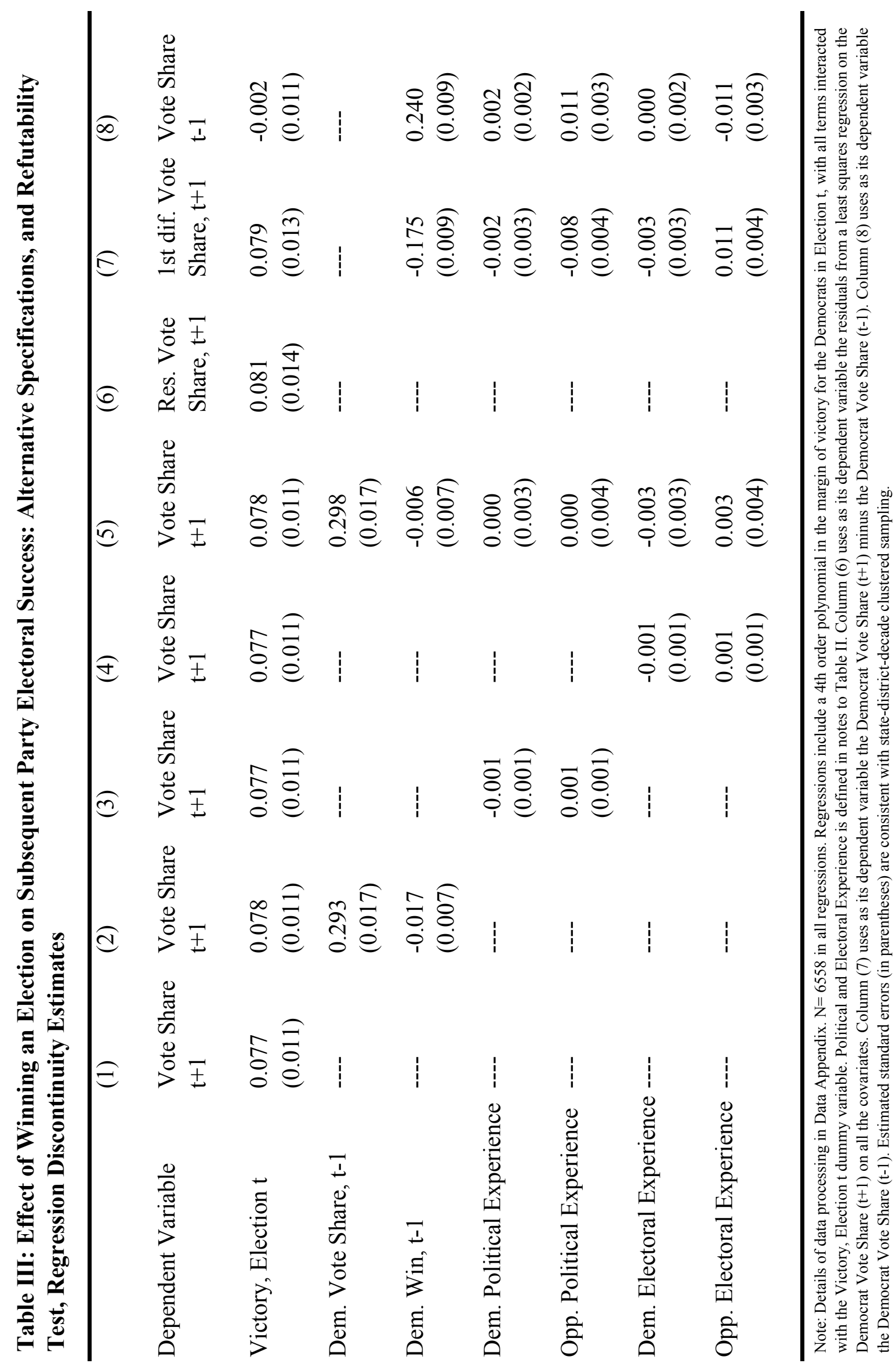


Table IV: Effect of Winning an Election on Candidate Electoral Success, Candidacy, and Party Vote Share and Electoral Success: Overall and by Experience (t) groups, Regression Discontinuity Estimates

\begin{tabular}{lllll}
\hline Dependent Variable $(\mathrm{t}+1)$ & $\begin{array}{l}\text { Candidate } \\
\text { Victory }\end{array}$ & $\begin{array}{l}\text { Candidate } \\
\text { Candidacy }\end{array}$ & $\begin{array}{l}\text { Party Vote } \\
\text { Share }\end{array}$ & $\begin{array}{l}\text { Party } \\
\text { Victory }\end{array}$ \\
$\begin{array}{llll}\text { Overall Estimate of Effect } \\
\text { of Victory (t) }\end{array}$ & $\begin{array}{l}0.450 \\
(0.031)\end{array}$ & $\begin{array}{l}0.434 \\
(0.032)\end{array}$ & $\begin{array}{l}0.078 \\
(0.011)\end{array}$ & $\begin{array}{l}0.385 \\
(0.036)\end{array}$ \\
\hline $\begin{array}{l}\text { Sub-groups, by Experience (t) } \\
\text { Experience=0 }\end{array}$ & 0.431 & 0.502 & 0.084 & 0.388 \\
& $(0.043)$ & $(0.039)$ & $(0.013)$ & $(0.052)$ \\
Interaction: & 0.027 & -0.181 & 0.004 & -0.114 \\
$0<$ Experience $<=2$ & $(0.104)$ & $(0.107)$ & $(0.031)$ & $(0.15)$ \\
Interaction & 0.008 & -0.123 & -0.116 & -0.249 \\
Experience $>2$ & $(0.09)$ & $(0.115)$ & $(0.052)$ & $(0.183)$ \\
p-value & 0.966 & 0.164 & 0.078 & 0.328 \\
F-test of Equal Coefficients & & & & \\
Sample Size & 9674 & 9674 & 6558 & 6558 \\
\hline
\end{tabular}

Note: Details of data processing in Data Appendix. Least Squares Estimates for for Democrat candidates in Election t. Estimated standard errors (in parentheses) are consistent with candidate-level clustering for the first two columns, and state-district-decadeclustered sampling, for the second two columns. Sub-groups defined by Political Experience as of Election t. All columns include a 4th order polynomial in the Democratic margin of victory (with interactions with sub-groups), and Political and Electoral Experience Variables (with subgroup interactions). Second two columns additionally include Democrat Vote Share and Victory Indicator (t-1). F-test is of the null hypotheses that both sub-group interactions are zero. 
Table V: Structural Estimation of Implicit Voters' Valuation of Political Experience, Overall and by Experience (t) Sub-groups: Regression Discontinuity Estimates and Alternative Estimation Approaches

\begin{tabular}{|c|c|c|c|c|}
\hline \multicolumn{5}{|l|}{ Regression Discontinuity Estimates } \\
\hline Sample & $\begin{array}{l}\text { Overall } \\
\text { (1) }\end{array}$ & $\begin{array}{l}\text { Exp. }=0 \\
\text { (2) }\end{array}$ & $\begin{array}{l}0<\operatorname{Exp}<=2 \\
\text { Interaction } \\
\text { (3) }\end{array}$ & $\begin{array}{l}\text { Exp.>2 } \\
\text { Interaction } \\
\text { (4) }\end{array}$ \\
\hline First stage Relationship & 2.832 & 2.656 & -0.364 & 1.101 \\
\hline Effect of Victory on Exp. Dif. & $(0.311)$ & $(0.287)$ & $(0.514)$ & $(0.982)$ \\
\hline $\begin{array}{l}\text { Reduced-Form Relationship } \\
\text { Effect of Victory on Vote Share } \\
\text { Index }\end{array}$ & $\begin{array}{l}0.208 \\
(0.027)\end{array}$ & $\begin{array}{l}0.222 \\
(0.032)\end{array}$ & $\begin{array}{l}-0.124 \\
(0.067)\end{array}$ & $\begin{array}{l}0.002 \\
(0.092)\end{array}$ \\
\hline $\begin{array}{l}\text { Structural Parameter: Implicit } \\
\text { Value of a Year of Experience }\end{array}$ & $\begin{array}{l}0.073 \\
(0.012)\end{array}$ & $\begin{array}{l}0.084 \\
(0.014)\end{array}$ & $\begin{array}{l}-0.041 \\
(0.029)\end{array}$ & $\begin{array}{l}-0.034 \\
(0.025)\end{array}$ \\
\hline \multicolumn{5}{|l|}{ Alternative Estimation Approaches } \\
\hline Cross-sectional OLS & $\begin{array}{l}0.060 \\
(0.002)\end{array}$ & $\begin{array}{l}0.052 \\
(0.003)\end{array}$ & $\begin{array}{l}0.032 \\
(0.012)\end{array}$ & $\begin{array}{l}-0.031 \\
(0.004)\end{array}$ \\
\hline $\begin{array}{l}\text { "Fixed Effect" (Differencing) } \\
\text { Estimator }\end{array}$ & $\begin{array}{l}0.022 \\
(0.003)\end{array}$ & $\begin{array}{l}0.031 \\
(0.005)\end{array}$ & $\begin{array}{l}0.000 \\
(0.008)\end{array}$ & $\begin{array}{l}-0.016 \\
(0.007)\end{array}$ \\
\hline $\begin{array}{l}\text { Instrumental Variable Estimate } \\
\text { (Victory in Election } \mathrm{t} \text { as } \\
\text { Instrument) }\end{array}$ & $\begin{array}{l}0.103 \\
(0.002)\end{array}$ & $\begin{array}{l}0.151 \\
(0.006)\end{array}$ & $\begin{array}{l}0.018 \\
(0.014)\end{array}$ & $\begin{array}{l}-0.065 \\
(0.008)\end{array}$ \\
\hline Sample Size & 5186 & 5186 & ---- & ---- \\
\hline
\end{tabular}

